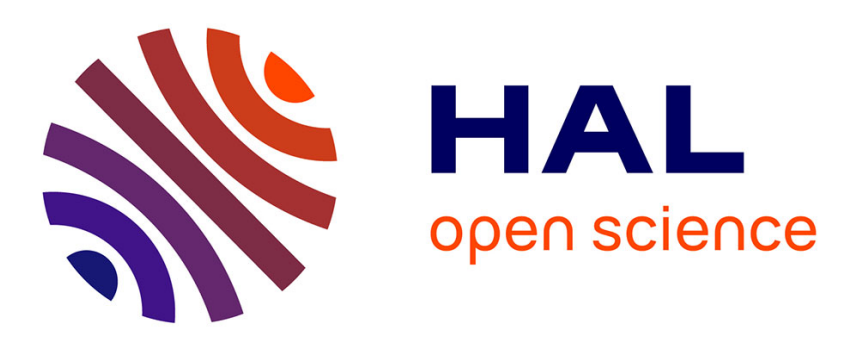

\title{
Towards the deformability of triaxial braided composite reinforcement during manufacturing
}

Shenglei Xiao, Peng Wang, Damien Soulat, Xavier Legrand, Hang Gao

\section{To cite this version:}

Shenglei Xiao, Peng Wang, Damien Soulat, Xavier Legrand, Hang Gao. Towards the deformability of triaxial braided composite reinforcement during manufacturing. Composites Part B: Engineering, 2019, 169, pp.209 - 220. 10.1016/j.compositesb.2019.04.017 . hal-03480690

\section{HAL Id: hal-03480690 \\ https://hal.science/hal-03480690}

Submitted on 20 Dec 2021

HAL is a multi-disciplinary open access archive for the deposit and dissemination of scientific research documents, whether they are published or not. The documents may come from teaching and research institutions in France or abroad, or from public or private research centers.
L'archive ouverte pluridisciplinaire HAL, est destinée au dépôt et à la diffusion de documents scientifiques de niveau recherche, publiés ou non, émanant des établissements d'enseignement et de recherche français ou étrangers, des laboratoires publics ou privés.

\section{다(1) $\$$}

Distributed under a Creative Commons Attribution - NonCommercial| 4.0 International 


\title{
Towards the deformability of triaxial braided composite
}

\section{reinforcement during manufacturing}

\author{
Shenglei Xiao ${ }^{1,2}$, Peng Wang ${ }^{2,} *$, Damien Soulat ${ }^{2}$, Xavier Legrand ${ }^{2}$, Hang Gao ${ }^{1}$ \\ ${ }^{1}$ Key Laboratory for Precision and Non-traditional Machining Technology of Ministry of \\ Education, School of Mechanical Engineering, Dalian University of Technology, Dalian, \\ 116024, China \\ ${ }^{2}$ University of Lille, Ensait, Gemtex, F-59000 Roubaix, France \\ * Corresponding author. Tel.: +33 3202589 47. Fax.: +33 320256461. \\ E-mail address: peng.wang@ensait.fr
}

\begin{abstract}
:
At the first stage of the Resin Transfer Molding (RTM) process, the composite reinforcements preforming is a complicated physical stage including complex deformability behaviours. In this paper, the deformability of carbon triaxial braided fabrics, one of the advanced composite reinforcements, is originally investigated. The yarns sliding along both longitudinal and radial yarn directions is the primary preforming behaviour, which is quite distinct from the woven fabrics preforming. Moreover, the yarns sliding along two yarn directions present quite a difference between the axial and bias yarns. The manufacturing defects during the triaxial braided fabrics preforming such as fibre vacancies, buckling and gaps are also discussed. At last, the geometrical models to predict maximum sliding along longitudinal yarn direction are described based on basic preforming parameters. Besides, the criterion preventing fibre vacancies are also proposed.
\end{abstract}

Keywords: Textile composites; Forming; Braided reinforcement; Sliding. 


\section{Introduction}

In the manufacturing composites parts with complex shapes, the Liquid Composite Moulding (LCM) processes can provide good performances in terms of repeatability, production rate, low-energy consumption and low final cost [1-3]. The preforming of dry reinforcement is the first step of these processes before the resin infusion/injection. However, the composite reinforcements preforming is a difficult stage that includes the complex mechanical behaviours, which are influenced by many process parameters such as the preforming load, the initial orientation of yarns, the properties of yarns and the shape of tools [4]. Hence, it is complicated to precisely characterise the deformability behaviours during preforming stage. Moreover, the preforming defects observed at different scales (mesoscopic and macroscopic scales), such as buckling, wrinkling, and misalignment [5-8], are heavily associated with preforming behaviours. These defects can bring negative influences on the resin impregnation, and critical changes of the in-plane and through-thickness permeabilities $[4,9,10]$. Consequently, in order to produce the complex geometric composite parts without defects, it is important to acquire the deformability behaviours during preforming.

Braiding is commonly used for fabricating reinforcements during composites manufacturing due to the advantages such as increased toughness, control over fibre deposition angle, and fast fibre deposition rate [11-17]. Hence, many types of research have described these reinforcements, their mechanical properties, their applications and the braiding process. This growing interest is justified firstly by the process $[16,18]$, which competes well with filament winding, pultrusion and tape lay-up [19,20]. In contrast, the weaving process is unable to produce non-orthogonal reinforcement $[21,22]$. Compared to woven fabrics the material orientations in braids are not necessarily orthogonal, and braids can be produced into many shapes such as tubular, rods and flat (opened). Especially for triaxial braids, which contain the axial yarns added along the longitudinal axis as third 
material orientation, leading to high fibre volume fraction for mechanical applications. Braided reinforcements are conventionally used as tubular (or circular) braided fabrics, but the flat braids is a new way to obtain the $2 \mathrm{D}$ non-orthogonally textile reinforcements. It is interesting to analyse the flat braided fabrics preforming process as the first stage of Resin Transfer Molding.

Preforming defects can be experienced during the composites manufacturing. Wrinkling is one of the most common preforming defects at macroscale considering the effects on in-plane shearing and bending $[23,24,40]$. The methods such as finite element and experimental analysis were utilized to find out the correlation between the processing parameters like blank-holder pressure and wrinkle $[6,23,24]$ and finally to optimise the preforming stage [2527]. But the preforming defects characterised at macroscale or mesoscale are more difficult to quantify, in particular for the complex shapes with high curvatures and large deformations $[28,29]$. The sliding of the network, which can be defined as inter-ply sliding in multilayer preforming or inter-yarn sliding in monolayer preforming, is another preforming defect that has a negative influence on the preforming quality. The inter-ply sliding denoted by the relative movements of the plies induces the local wrinkles $[3,30]$. In contrast, the yarns sliding depending on the blank-holder pressure is experimentally defined in [4]. Gatouillat et al. presented numerically that excessive sliding between warp/weft yarns can lead to a loss of cohesion in the woven network [31]. In this case, the tow or yarn orientation cannot be controlled during the preforming and the local fibre density decreases. Consequently, a decrease in local fibre density can influence the resin impregnation and may lead to the resinrich zone in final composite parts, the mechanical properties hence would be impacted undesirably.

Although the deformability behaviours during the preforming have been widely recognized and investigated in many perspectives, the previous researches mainly focused on the woven 
or NCF (Non-crimp-Fabrics) fabrics with different punch shapes such as hemisphere [32-34], double-dome [27,35,36], eccentric cone [37], tetrahedral and square box [38-42]. On the contrary, even though Jacquot et al. [43] compared the deformability behaviours of woven and biaxial braided fabrics manufactured from the same comingled flax/PA12 yarns on the hemispherical punch, there are relatively few research works dealing with the braided reinforcements preforming. As one of the promising textile composite reinforcements, triaxial braids have a specific structure since their deformability behaviours are possibly different from the classical biaxial textile fabrics (woven or biaxial braided fabrics). Unfortunately, due to the lack of systematic research in deformability behaviours of triaxial fabrics, the difference between biaxial and triaxial fabrics in preforming does not draw enough attention.

Therefore, in the present study, the triaxial braided fabrics made by continuous carbon yarns are firstly studied in hemispherical preforming. Characteristics of deformability behaviours are discussed and analysed with varied blank-holder pressures. Then, the correlation between the preforming defects and behaviours are illustrated. At last, the geometrical models to describe the special behaviour and to prevent one potential defect are also originally proposed.

\section{Material and methods}

\subsection{Tested braided reinforcements}

The triaxial braids are produced by continuous carbon yarns under overbraiding process [43]. The braiding angle can be imposed during overbraiding process thanks to selecting the appropriate process parameters. After the braiding process, the braided fabrics are carefully cut and opened to obtain two-dimensional reinforcements avoiding modification of the braiding angle (Fig. 1a). In the fabric scale (macroscopic scale), the axial and transversal directions of fabric are clearly marked in Fig.1a. In the single yarn scale (mesoscopic scale), the two directions, longitudinal and radial yarn directions, which are along and perpendicular 
to the central line of single yarn respectively, are also described in Fig.1b. These two directions are important to further analyse the sliding behaviour. As shown in Fig.1c, the triaxial braid is flattened and characterized by axial yarns along the axial direction of fabric interlaced with bias yarns. The characteristics of the tested braided fabric are presented in Table 1. In order to directly present special preforming behaviours of triaxial braids, the woven fabric is put forward as contrast. Table 2 shows the characteristics of the woven fabric.

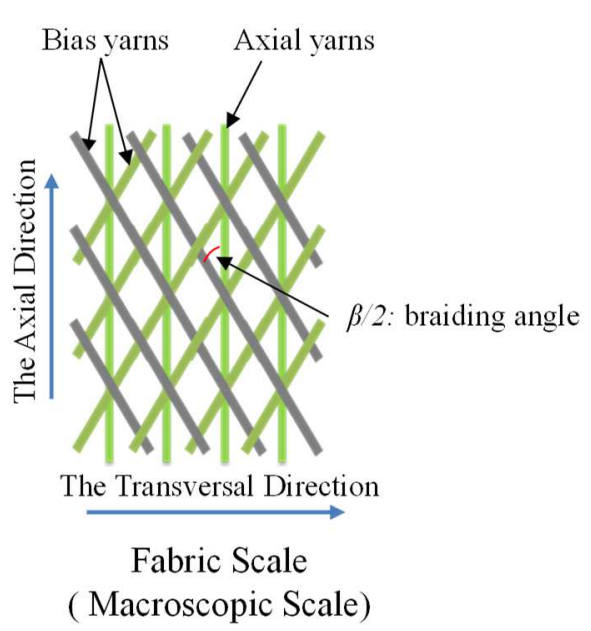

(a)

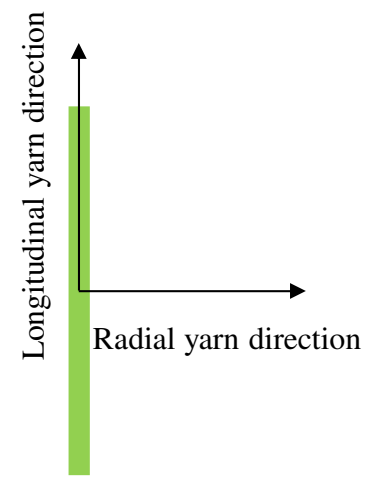

Single Yarn Scale ( Mesoscopic Scale)

(b)

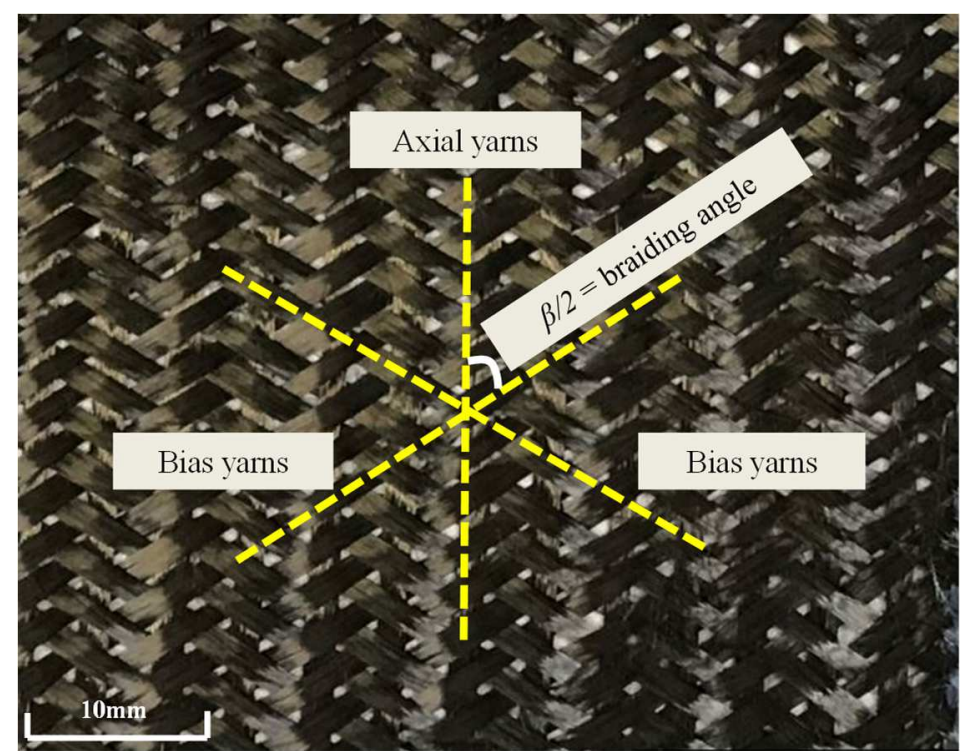

(c)

Fig. 1. Tested triaxial braided reinforcement, (a) 2D structure, (b) a single yarn profile and (c) the specific profile.

Table 1 
The main properties of the tested braided fabric.

\begin{tabular}{cc}
\hline Parameters & Value \\
\hline Yarns & 792 tex \\
Area density $\left(\mathrm{g} / \mathrm{m}^{2}\right)$ & $510 \pm 5$ \\
Thickness $(\mathrm{mm})$ & 2.37 \\
Braiding angle $\left({ }^{\circ}\right)$ & 55 \\
Number of yarns per cm & 3.9 \\
Surface dimensions $\left(\mathrm{mm}^{2}\right)$ & $280 \times 280$ \\
Yarn width $(\mathrm{mm})$ & 4.0 \\
Distance between two adjacent axial & $4.0 \pm 0.5$ \\
yarns- $L_{0}(\mathrm{~mm})$ & $1.3 \pm 0.2$ \\
Distance between two adjacent bias & \\
yarns- $L_{0}^{\prime}(\mathrm{mm})$ &
\end{tabular}

\section{Table 2}

The main characteristics of the tested woven fabric.

\begin{tabular}{cc}
\hline Parameters & Value \\
\hline Type of fabric & Twill $2-2$ \\
Area density $\left(\mathrm{g} / \mathrm{m}^{2}\right)$ & $600 \pm 5$ \\
Thickness $(\mathrm{mm})$ & 0.62 \\
Number of warps per cm & 3.7 \\
Number of wefts per cm & 3.7 \\
Surface dimensions $\left(\mathrm{mm}^{2}\right)$ & $280 \times 280$ \\
\hline
\end{tabular}

\subsection{Preforming machine and the experimental set-up}

The specific preforming device developed at the GEMTEX laboratory is used as the experimental machine in Fig. 2 [41]. The tested fabric can be put between the upper plate and die since the upper plate is moveable. The blank-holder driven by a pneumatic jack permits the pressure on the fabric during the preforming. In these tests, the varied parameters are only blank-holder pressures that can be selected at 0.05, 0.1, 0.2 and $0.3 \mathrm{MPa}$, and every value is performed by three fabrics in order to verify the repeatability of results. The hemispherical punch with $140 \mathrm{~mm}$ diameter is given a constant movement $(45 \mathrm{~mm} / \mathrm{min})$ by the lower pneumatic jack equipped with a sensor that could measure the punch force in real time.

In order to conveniently analyse the preforming behaviours, in particular, the yarns sliding, the axial and bias yarns should be numbered before preforming. The axial yarns from the centre of fabric along the transversal direction are numbered as shown in Fig. 3. Since the 
number of axial yarns within the hemisphere shape after preforming is approximately twelve, the number thus in Fig. 3 is from 0 to 11. Due to symmetrical profiles of hemispherical punch shape and square fabric, the axial yarn that coincides with the central line of punch shape, is almost constant before and after preforming since the central axial yarn of fabric only sustained out-plane bending. Thus, the central axial yarn of fabric is considered as $\mathrm{N}^{\circ} 0$ and the $L_{0}$ (in Table.1) is defined and measured as the initial distance between axial yarns before preforming. By the same definition method, the bias yarns can also be numbered (see Fig. 3) and $L^{\prime}{ }_{0}$ is also defined and measured.

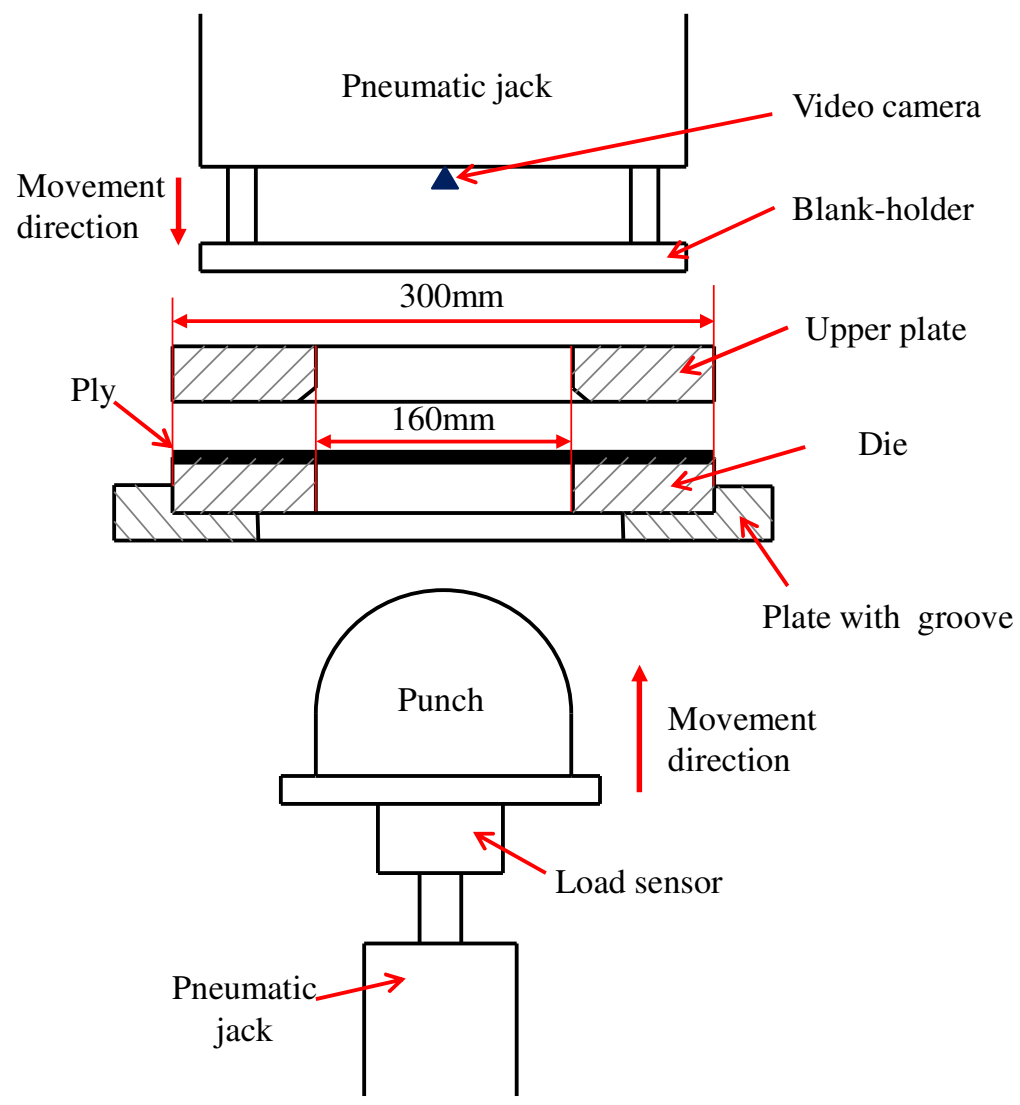

Fig. 2. Details of preforming device.

After preforming but before blank-holder moving back ("demoulding"), the deformed fabric in the preforming device can be fixed using the certain settling agent in order to avoid the elastic spring-back. A video camera installed on the device and linked with a computer is used to monitor preforming process and measure the evolution of yarn sliding. After the 
consolidation of the settling agent, the blank-holder moves back to the original position and the deformed fabric is moved outside from the device for further measurement.

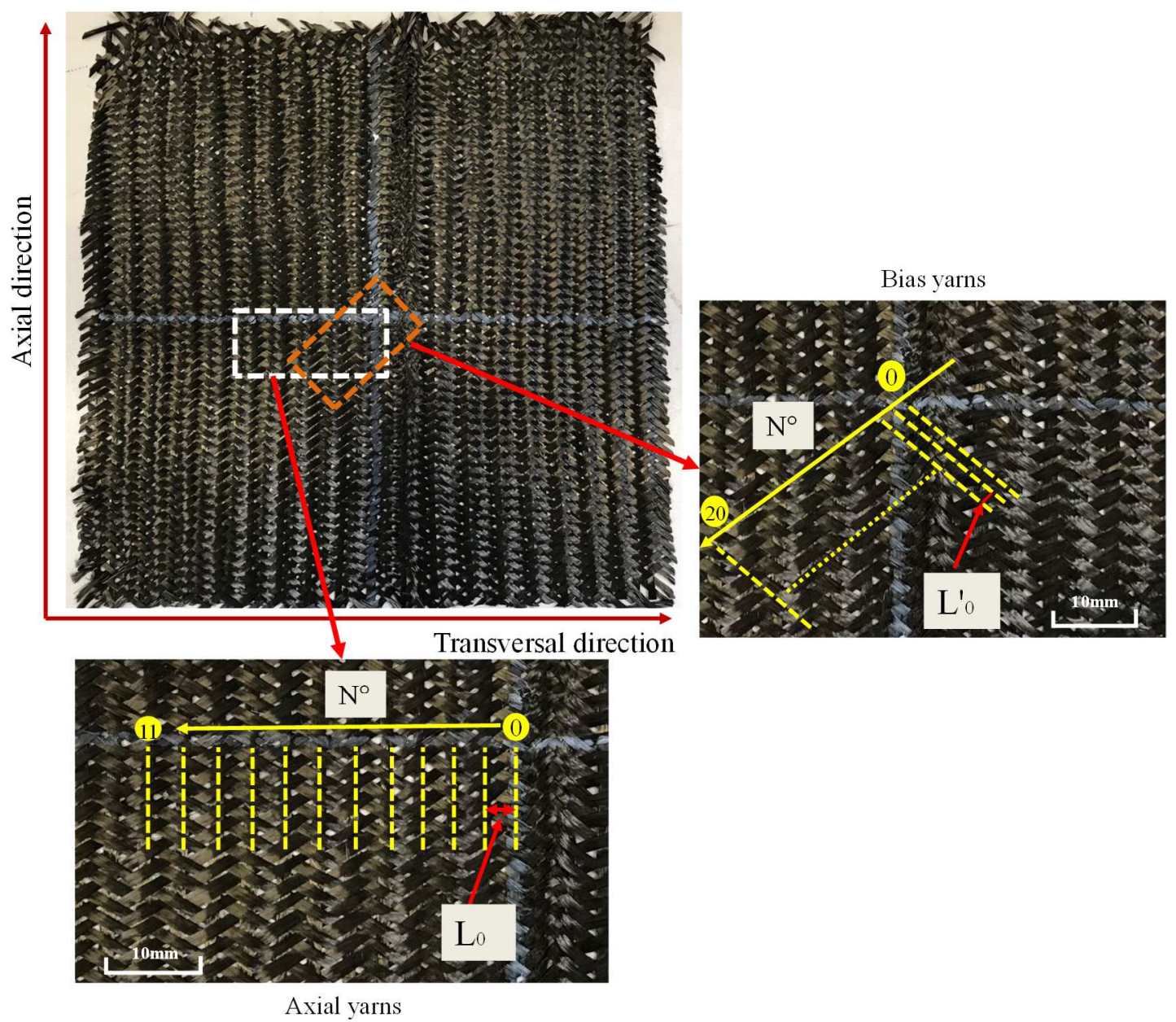

Fig. 3. Braided fabric before preforming and numbered yarns.

\section{Results and discussion}

The braided fabric after the preforming with a blank-holder pressure of $0.1 \mathrm{MPa}$ can be observed in Fig. 4. The yarns sliding and in-plane shear zones can be clearly seen as symmetrical profiles. In contrast, preforming of the woven fabric produced by the same carbon yarns with braided fabric is showed in Fig. 5, which shows a global displacement (material draw-in) clearly in two directions. Moreover, compared to the deformed woven fabric, only two in-plane shear zones can be observed in the transversal direction in triaxial braided fabrics due to the unbalanced structure of the braided fabric. Be different from the 
hemispherical preforming of the woven fabrics, this unbalanced distribution of in-plane shear was also observed in the preforming of the biaxial braided fabrics [43]. The unbalanced structure of tested triaxial braids exhibits two different characteristics under tension along axial and transversal directions of fabric. The following sections will discuss specific deformability behaviour of triaxial braided fabric, as well as the corresponding defects that could impact the quality of composites parts.

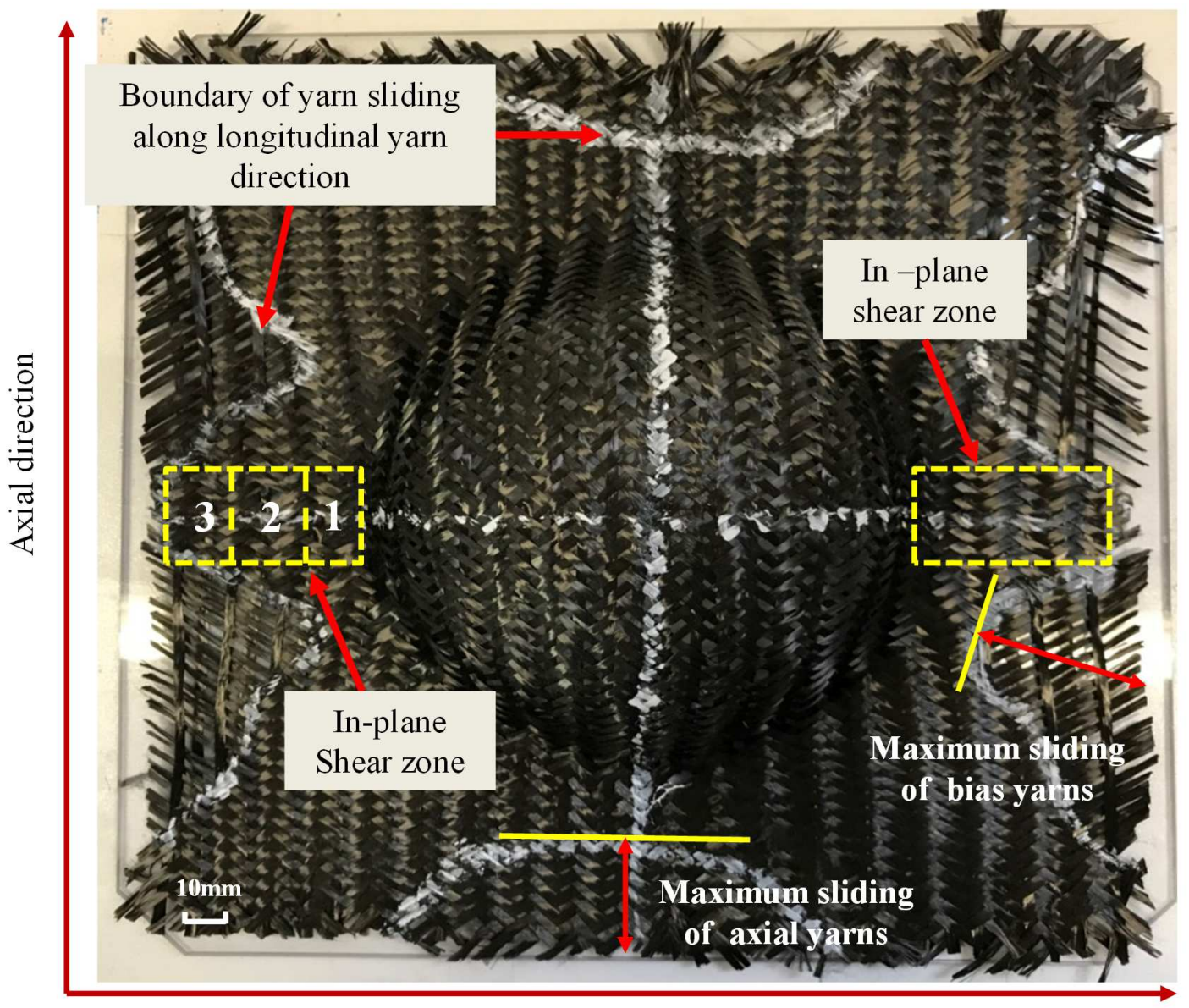

Transversal direction

Fig. 4. The triaxial braided fabric after preforming. 


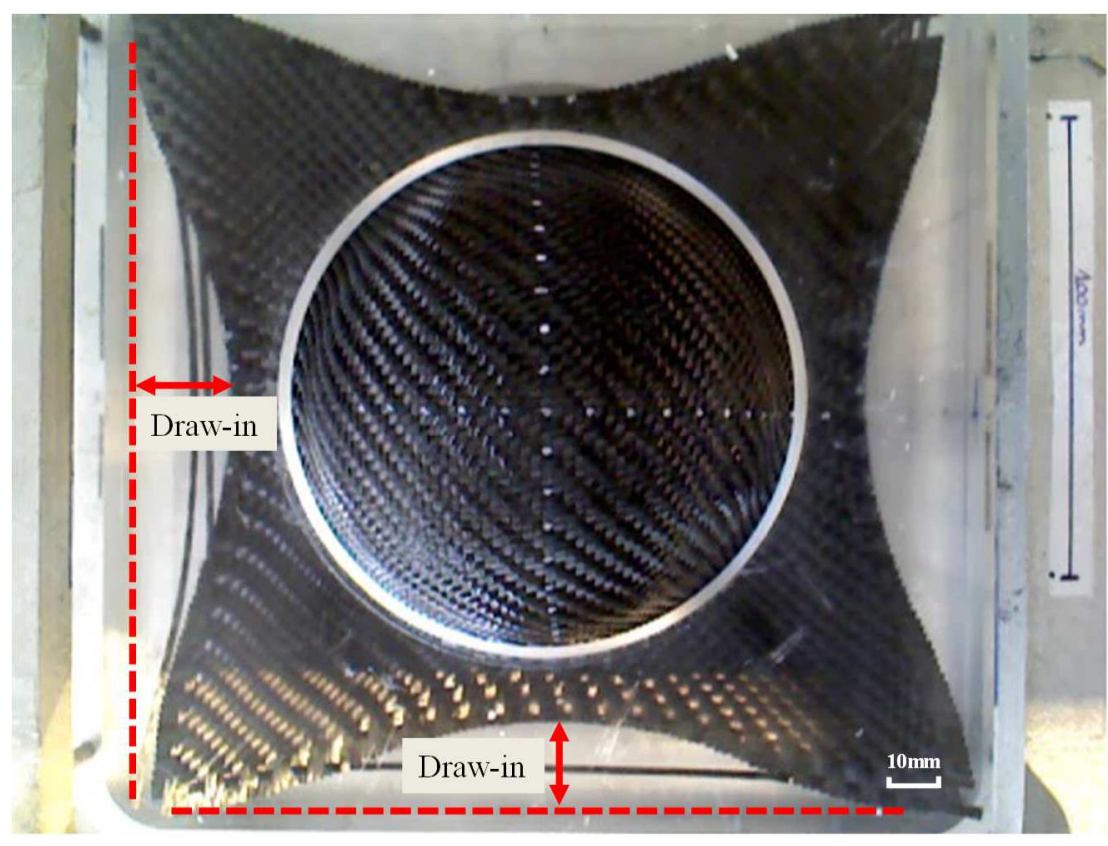

Fig. 5. The carbon woven fabric after hemispherical preforming.

\subsection{Yarns sliding}

\subsubsection{The sliding along longitudinal yarn direction}

The yarns sliding can be naturally divided along longitudinal and radial yarn directions at the mesoscopic scale (see Fig.1b). The yarns sliding along longitudinal yarn direction is induced by the out-plane bending in the useful zone. However, axial and bias yarns show different situations. The analysis of yarn sliding is based on the quasi-inextensibility since the carbon yarns almost have no extension.

\section{The axial yarns sliding along longitudinal yarn direction}

In Fig. 4 it is clearly seen that axial yarns sliding along longitudinal yarn direction can be approximately profiled as half ellipse marked by white lines at the axial direction of the fabric. The central axial yarn $\left(\mathrm{N}^{\circ} 0\right.$ defined in Fig.3) has maximum sliding because it is imposed the maximum out-plane bending displacement. Since the length of axial yarns sustaining outplane bending at the useful zone is symmetrical to transversal direction of the fabric, the axial yarns sliding along longitudinal yarn direction at the ends of axial yarns is almost identical. 
Fig. 6 shows the maximum punch force and the maximum axial yarn sliding along longitudinal yarn direction during the preforming with different blank-holder pressures. It can be observed at first that the augments of the blank-holder pressure lead to the increase of the punch force as expected. Remarkably, the maximum sliding nearly does not increase with blank-holder pressures. According to [44], the friction of tow-on-tow and tow-on-tool is too small to restrict the axial yarns slippage even though at maximum pressure. Thus, the sliding is dependent on the yarn length under blank-holder. At the same punch shape, the maximum sliding is almost identical.

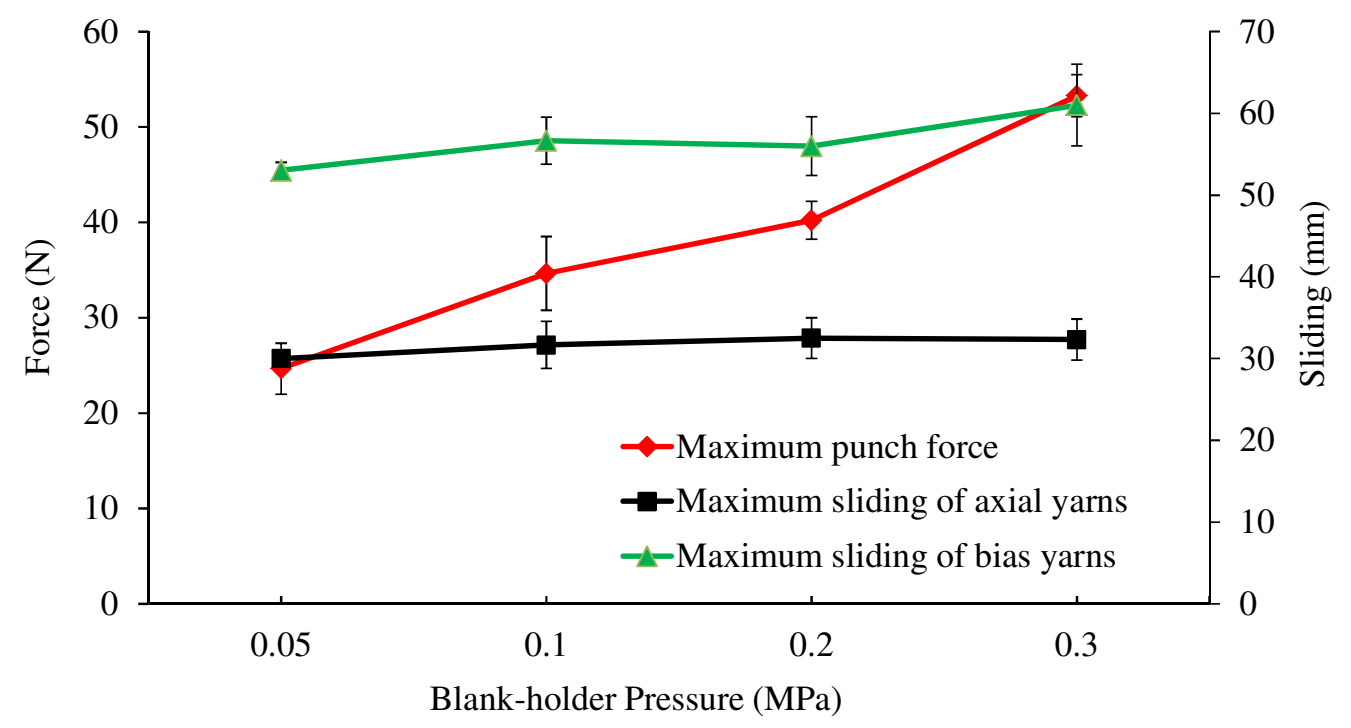

Fig. 6. Maximum sliding along longitudinal yarn direction in function of different blank-

holder pressures.

\section{$\underline{\text { The bias yarns sliding along longitudinal yarn direction }}$}

Bias yarns along longitudinal yarn direction can be profiled in Fig. 7a. Such sliding presents the difference compared to axial yarns sliding along the same direction. In Fig. 7a, except for bias yarn across the centre of punch shape $\left(\mathrm{N}^{\circ} 0\right.$ bias yarn in Fig.3), the other bias yarns show the uneven sliding at the ends of yarn. One end with a relatively shorter distance to the base of punch shape could slide with a larger extent due to the unequal friction induced by the ends of yarn. Fig. $7 \mathrm{~b}$ clearly shows the behaviour of this bias yarn sliding. Thus, the 
maximum sliding can be produced by only one end of yarn sliding, another end does not move at all (bias yarns with yellow colour in Fig.7a). Some bias yarns around the base of punch shape almost do not slide due to insufficient out-plane bending that cannot result in sliding. In addition, increasing blank-holder pressure almost has no effect on maximum bias yarns sliding along longitudinal yarn direction as shown in Fig.6.

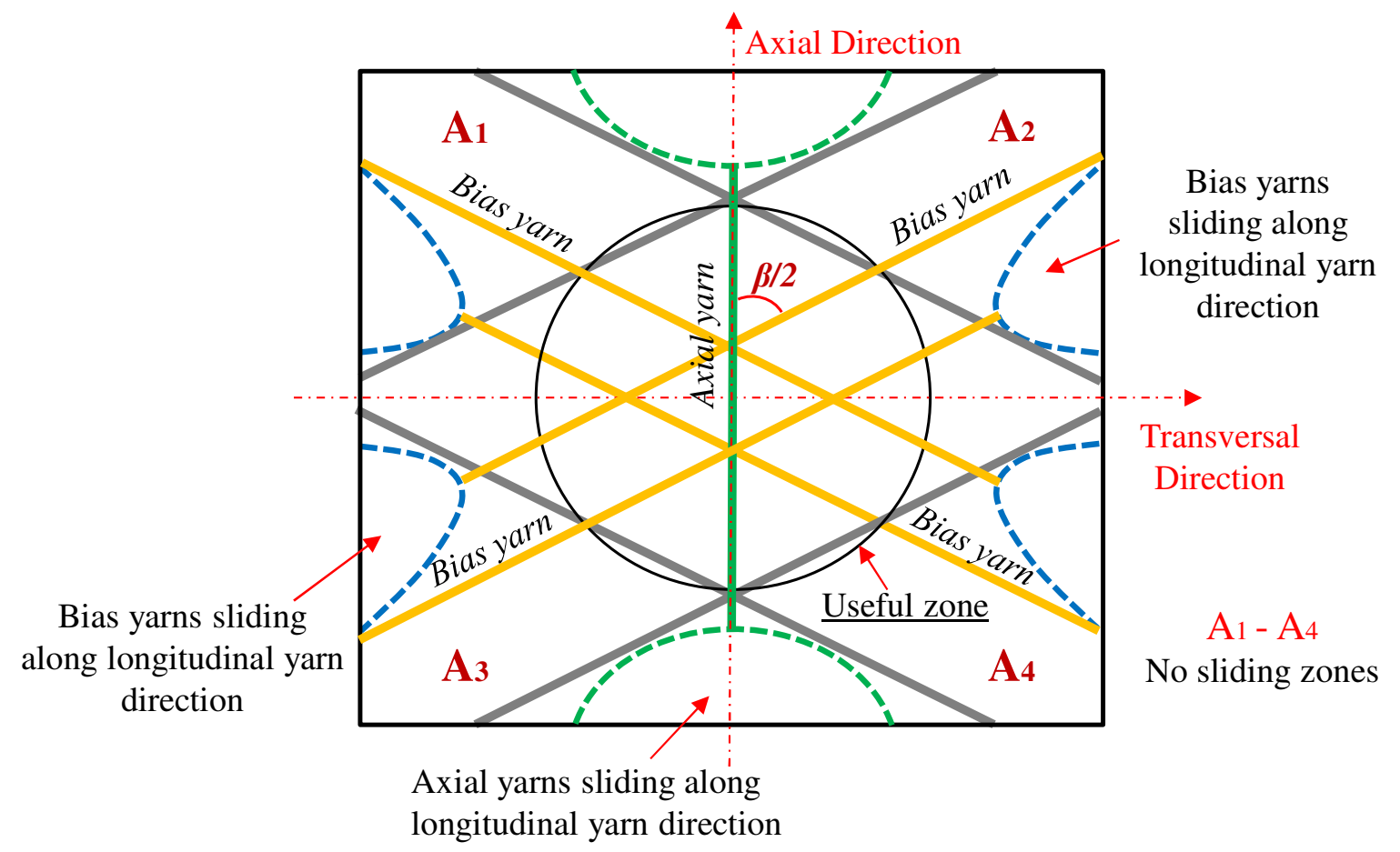

(a)

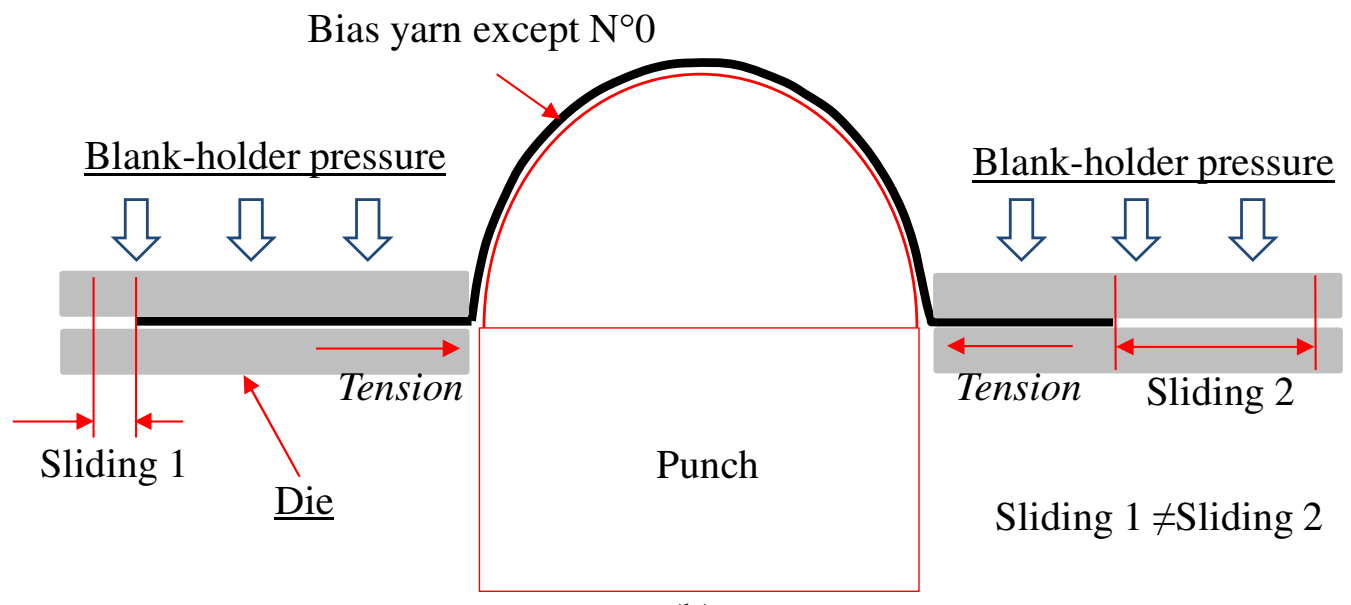

(b)

Fig. 7. The yarn sliding along longitudinal yarn direction, (a) the overall profile of sliding performance and (b) the non-identical sliding of bias yarns. 


\subsubsection{The sliding along radial yarn direction}

The yarns in the useful zone not only sustain tension along longitudinal yarn direction but also bear shear force along radial yarn direction, which originally generates another type of yarn sliding, the sliding along radial yarn direction. This sliding along radial yarn direction can be obviously observed for the axial yarns as shown in Fig. 8a.

\section{The axial yarns sliding along radial yarn direction}

Axial yarns numbered before preforming as shown in Fig. 3 can be counted from top to bottom of hemisphere shape after preforming. As shown in Fig. 8, the $L_{i}$ represents the vertical distance between the $\mathrm{N}^{\circ} i-1$ and $\mathrm{N}^{\circ} i$ axial yarns along the central line of hemisphere shape ( $i$ is the $\mathrm{N}^{\circ}$ of marked axial yarn shown in Fig. 3). This distance, which subtracts initial distance between two adjacent axial yarns before preforming $\left(L_{0}\right)$, could characterise the sliding of axial yarns along radial yarn direction. To calculate $L_{i}$, the vertical distance $\left(d_{i}\right)$ of each sliding axial yarn to $\mathrm{N}^{\circ} 0$ axial yarn could be firstly measured from the top view by an optical method. And then, the locations of axial yarns in the useful zone can be obtained geometrically on the $2 \mathrm{D}$ vertical plane (the plane passing through the central line) projected from the 3D useful zone (Fig.8b). Consequently, the sliding angle $\theta i$ defined in Fig. $8 \mathrm{~b}$ can be calculated. Then, the chord length between two adjacent axial yarns equal to $L_{i}$ can be calculated. Besides, $L_{i}$ is smaller at the base of the hemisphere as seen in Fig. 8 a because the portion of yarn is gradually restrained by blank-holder when it is close to the base of punch shape. Hence, axial yarns sliding along radial yarn direction is different along shape curve, and the maximum sliding distance is characterised along the central line of shape, which is used to evaluate the sliding along radial yarn direction. 


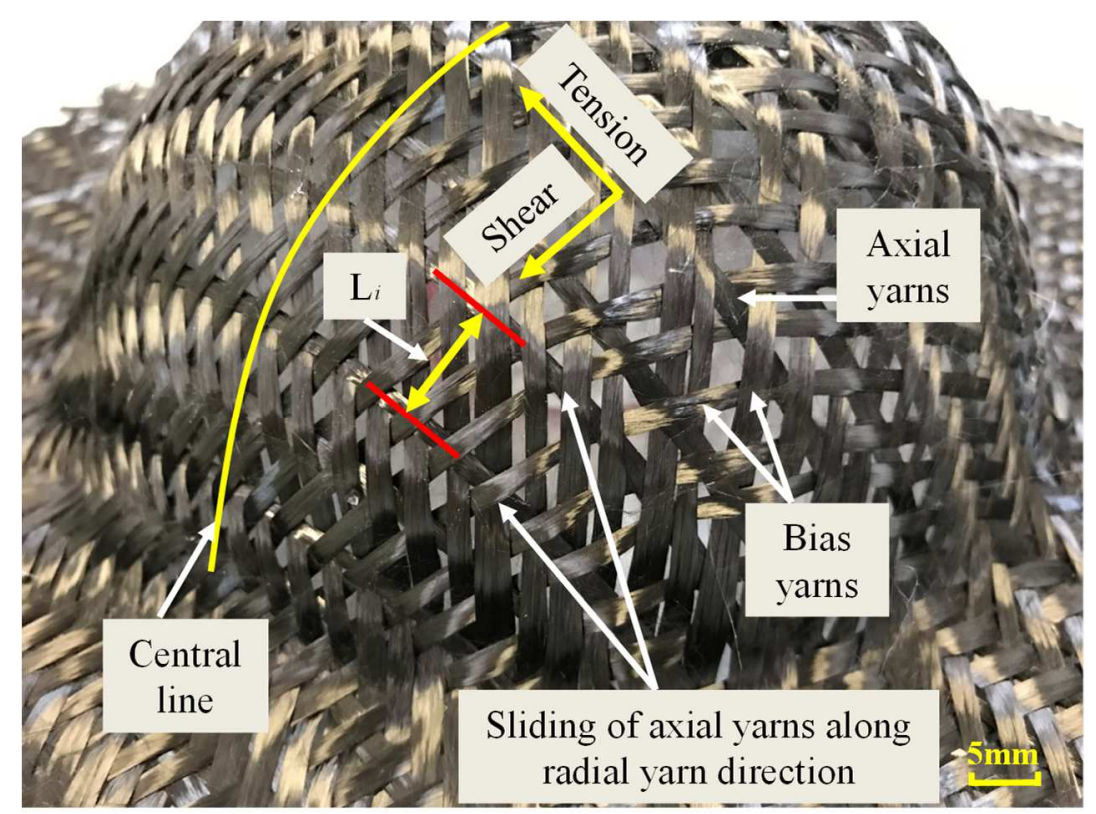

(a)

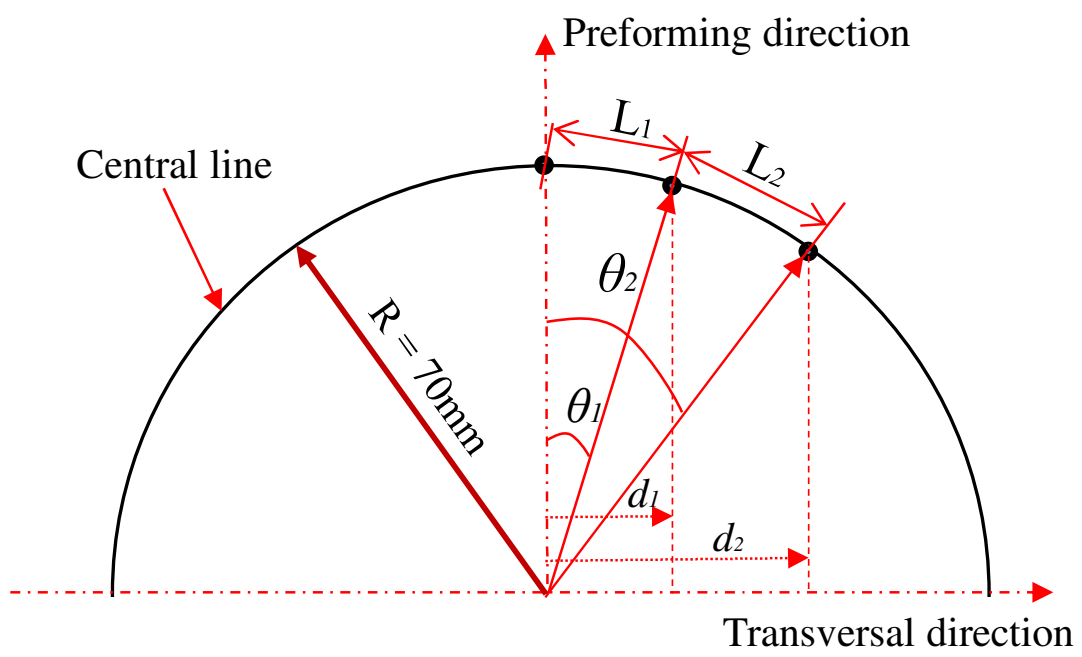

(b)

Fig. 8. Sliding of axial yarns along radial yarn direction, (a) the sliding phenomenon in the useful zone and (b) the depiction of sliding.

The axial yarns sliding along radial yarn direction with different pressures can be seen in Fig.9. Generally, the variation of axial yarns sliding along radial yarn direction shows a similar trend under different pressures. This trend can be divided into three parts. At first, regarding the four axial yarns around the top of the hemisphere $\left(1^{\text {st }}-4^{\text {th }}\right.$ yarn $)$, their sliding along radial yarn direction increases slightly (the maximum is about $2 \mathrm{~mm}$ ). In contrast, this sliding increases sharply in the second part $\left(5-8^{\text {th }}\right.$ yarn located around half hemisphere shape). 
The maximum sliding can approximately reach $2.5 \mathrm{~mm}$ with $0.05 \mathrm{MPa}$ and $8 \mathrm{~mm}$ with 0.2 MPa. Besides, the maximum sliding increases a little as pressures above 0.1MPa. After reaching the maximum sliding, the curves decline rapidly at the last three yarns $\left(9-11^{\text {th }}\right.$ yarn), which locates near the base of the hemisphere shape. Thus, the sliding of axial yarns along radial yarn direction is associated with the distance between the other yarns to the $\mathrm{N}^{\circ} 0$ yarn within the useful zone. This is because of non-uniform shear effects along the hemispherical surface during the preforming. However, 0.05 MPa shows the smallest component force in radial yarn direction, this sliding thus presents a low level. As a result, this non-uniform sliding generates the non-homogenous gaps between the axial yarns in the useful zone, resulting in nonhomogeneous density after the infusion stage in LCM process.

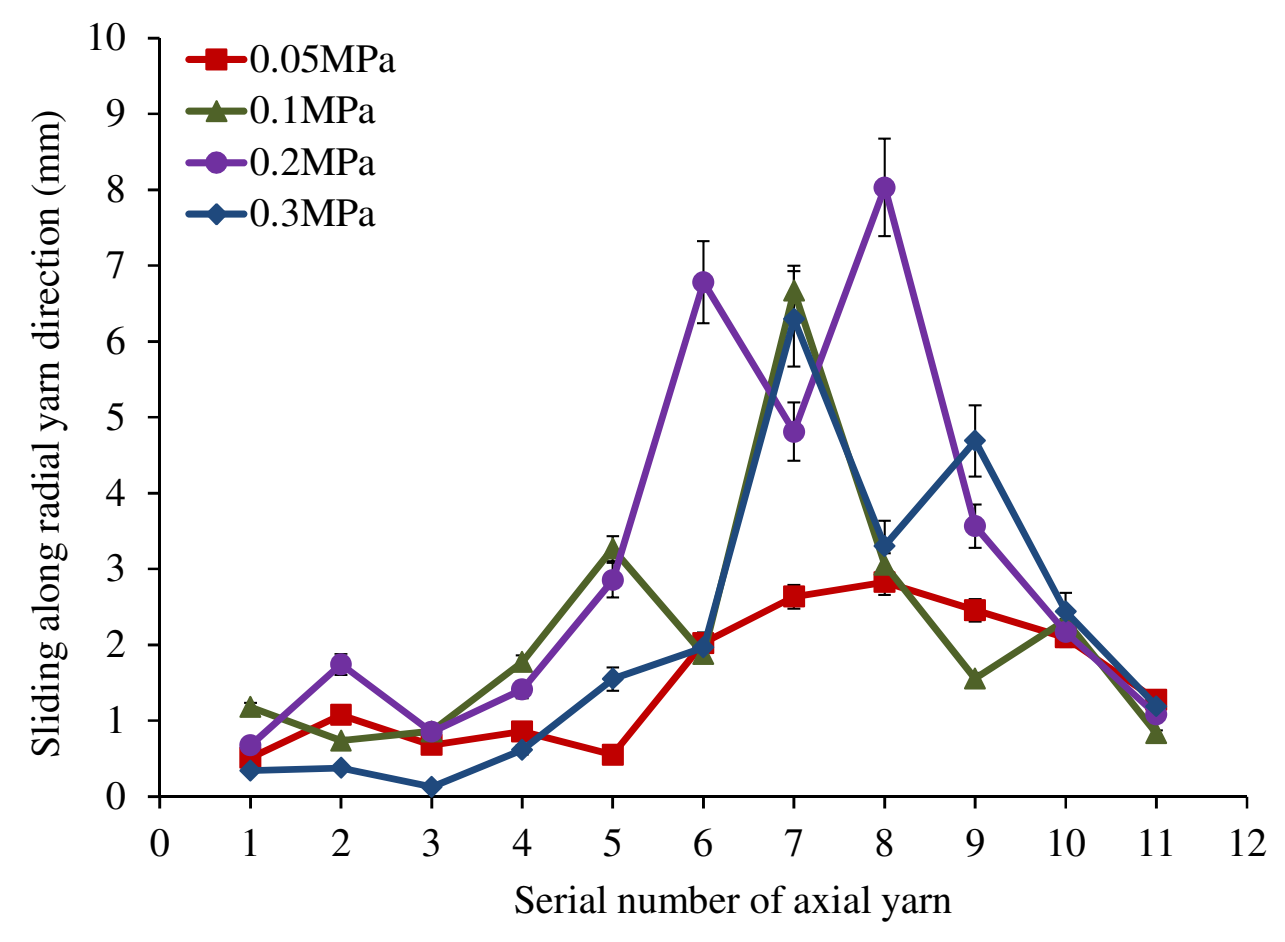

Fig. 9. Axial yarns sliding along radial yarn direction with different blank-holder pressures in the useful zone.

\section{$\underline{\text { The sliding of bias yarns along radial yarn direction }}$}

The sliding of bias yarns along radial yarn direction also can be observed in the useful zone as shown in Fig. 10. The way to calculate this sliding is same as axial yarns as the discussion 
above. The initial distance of bias yarns before preforming is about $1.3 \mathrm{~mm}$. The initial positions of the twenty bias yarns before preforming are shown in Fig. 3.

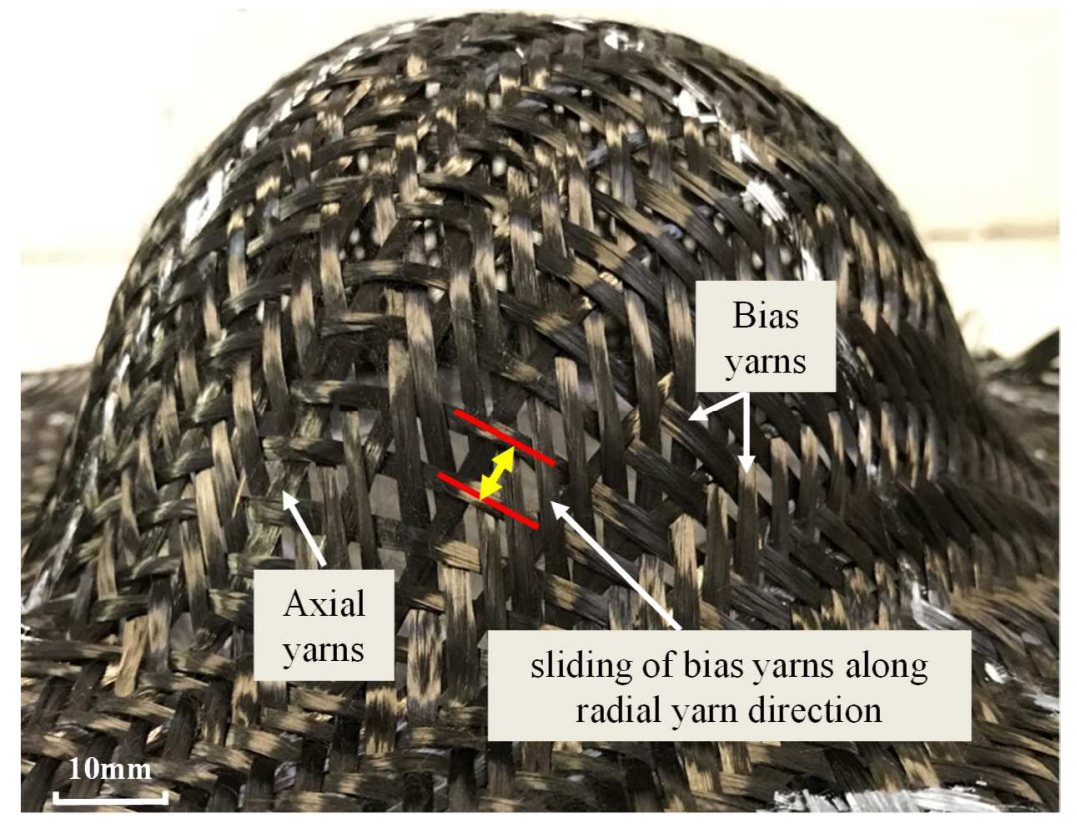

Fig. 10. The sliding of bias yarns along radial yarn direction in the useful zone.

Fig. 11 describes the sliding of bias yarns along radial yarn direction in the useful zone with different pressures. The tendency of the four curves is much similar. It is clearly observed that the sliding has a small increase in the first part $\left(1^{\text {st }}-5^{\text {th }}\right.$ yarn $)$, a big increase between $6-17^{\text {th }}$ yarn and a rapid decrease in the last part. It also can be remarked that the sliding generated by $0.05 \mathrm{MPa}$ is different from other pressures. The sliding increases slowly and the maximum sliding remains quasi-constant during the second part of the curve (increase 0.5-1.0 mm). The maximum sliding increases slightly when the blank-holder pressure is superior to $0.1 \mathrm{MPa}$. Therefore, it can confirm that the distance between other yarns to $\mathrm{N}^{\circ} 0$ yarn, i.e. the centre of hemisphere shape, is the key factor to influence the sliding along radial yarn direction when pressure over a certain value. 


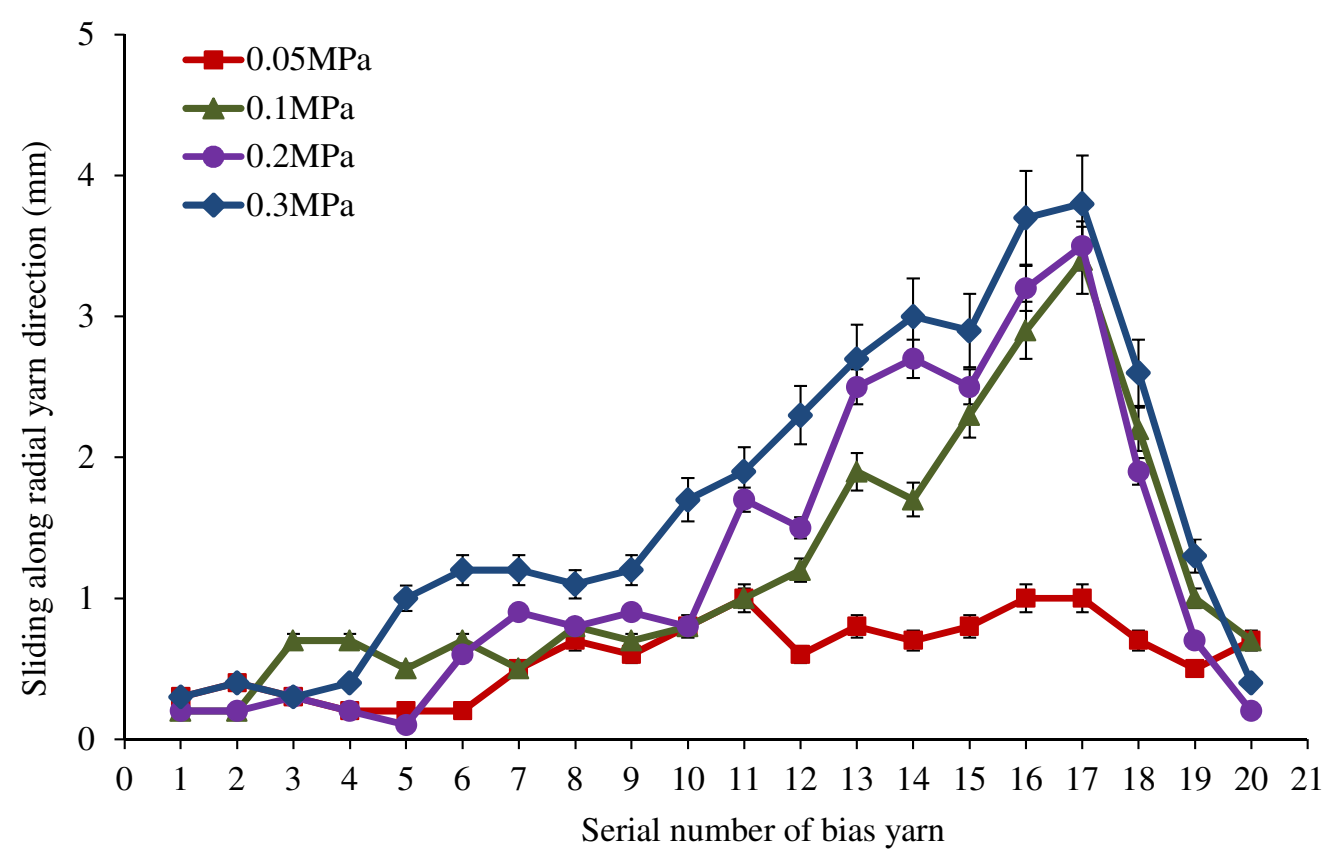

Fig. 11. The sliding of bias yarns along radial yarn direction with different pressures in the useful zone.

\subsection{In-plane shearing}

As mentioned previously (see Fig. 4), two in-plane shear zones can be observed on the deformed fabric. The ImageJ software can be used to measure the shearing angle after moving deformed fabrics from preforming device. As expected, the shearing action decreases gradually from the base of the punch shape to fabric boundary. Consequently, the measurements of the in-plane shear angle were performed at different three zones as shown in Fig.4. The first one is nearby the base of punch shape, the second one is in the middle of the shearing zone and the last one is closer to fabric boundary. These in-plane shear zones show the negative in-plane shear angles according to the classical definition of the in-plane shear angle $\gamma$ shown in Eq. 1. As demonstrated in Fig. 12, the negative in-plane shear angle is generated by the bias yarns turning outward during the deformation of the braided fabric.

$$
\gamma=\beta-\alpha
$$

where $\beta$ is two times the braiding angle and $\alpha$ is the angle between two bias yarns after deformation (see Fig. 12). $\alpha>\beta$ due to the rotation of bias yarns towards to the transversal 
direction. As the change in three in-plane shear angle measurement zones was small at interval $<2^{\circ}$, a mean shear angle was used to present the in-plane shear effect.

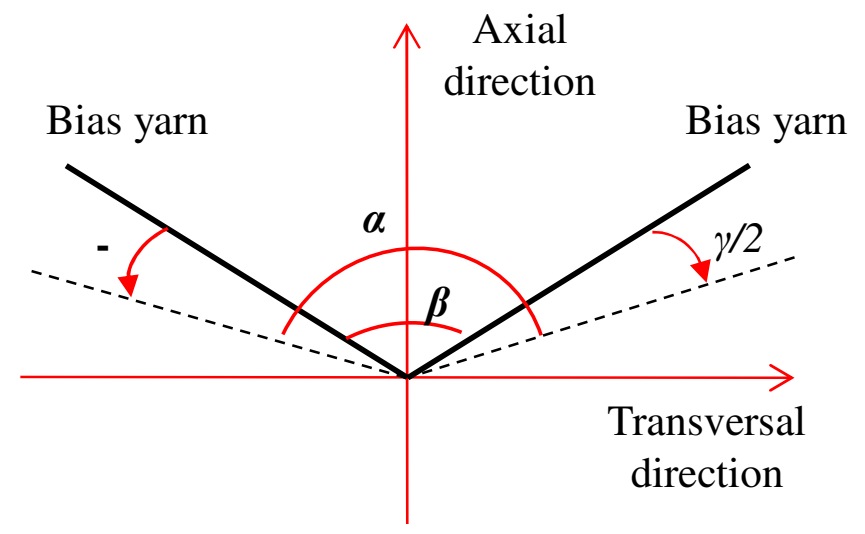

Fig. 12. The in-plane shearing towards to the transversal direction.

The maximum punch force and the mean in-plane shear angle $v s$. the blank-holder pressure are shown in Fig. 13. It is shown that the decrease in shear angle with increasing blank-holder pressure. As observed in Fig. 11, the increase of blank-holder pressure leads to an augmentation of the sliding of bias yarns along radial yarn direction (the gap between the bias yarns). In the useful zone, the bias yarns slide towards the base of punch shape and there is no sliding of the bias yarns in two in-plane shear zones marked in Fig. 4. The combination of these two phenomena creates the rotation of the yarns to turn inward, bring out the decrease of in-plane shear angle. 


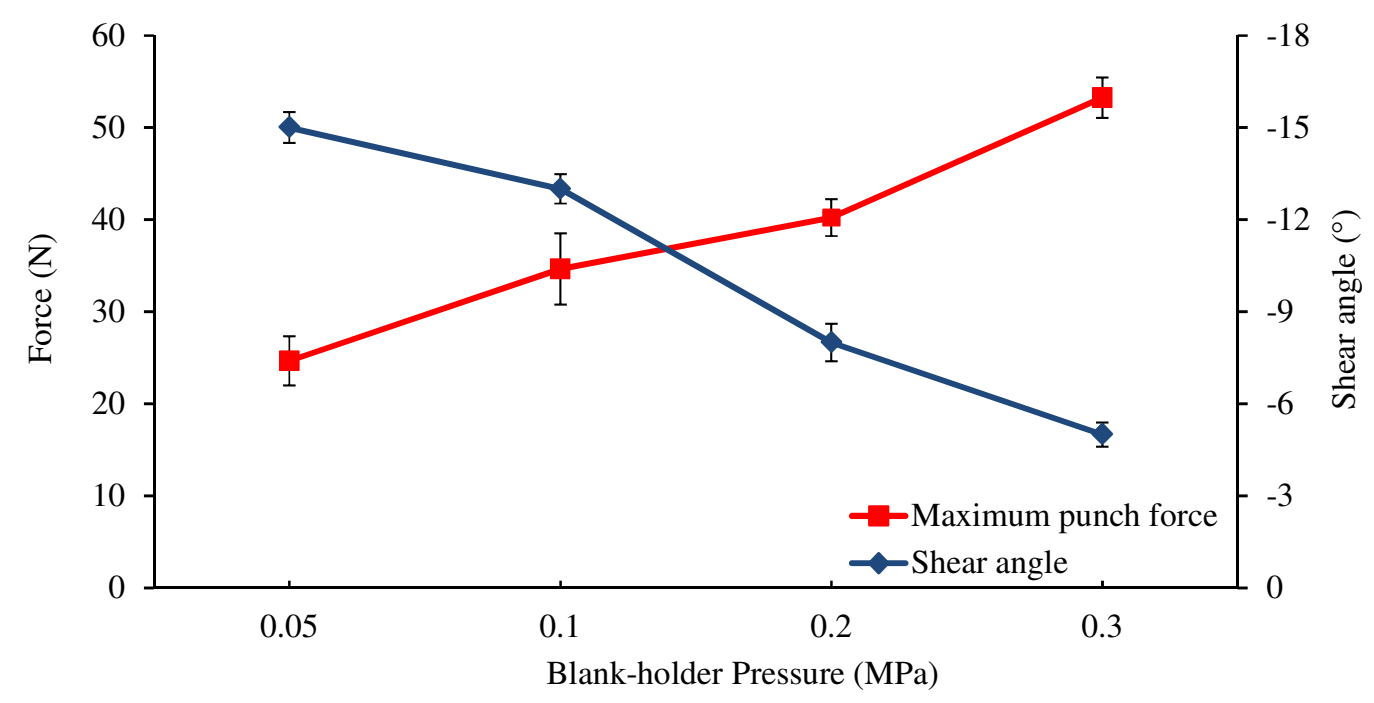

Fig. 13. The maximum punch force and the mean in-plane shear angle vs. the blank-holder pressure.

\subsection{Preforming defects}

Based on the analysis above, it is possible to perform double curvature shapes with the triaxial fabrics. However, the preforming defects are also observed and heavily related to basic input parameters. In general, the blank-holder system, which offers a sufficient tension level during the preforming, is important since it could effectively prevent the appearance of the wrinkling defect. By applying a sufficient tension on fabric, the compression effect can be annealed. Nevertheless, the special defect, fibre vacancies, could be produced after preforming if the parameters are not properly selected. The other normal defects, which can be observed after preforming woven fabrics such as gaps and buckling, are also clearly noticed.

\subsubsection{Fibre vacancies}

As described in section 3.1.1, the yarns sliding along longitudinal yarn direction cannot be prevented. Although this phenomenon at the useless zone is not necessary to consider, if this sliding steps into the useful zone, the sliding exceeds the residual distance depicted in Fig.14, the fibre vacancies would be generated locally. Thus, the nonhomogeneous permeability would happen and reduce the mechanical performance of final composite parts. The residual 
distance is defined as the distance between maximum sliding to the base of the punch shape. The extent of yarns sliding along longitudinal yarn direction can be determined by the parameters such as the diameter of the punch, the fabric dimensions and the braiding angle. Hence, the correlation among these parameters should be carefully considered by the composite part designer in order to avoid the excessive yarns sliding along longitudinal yarn direction. The simple geometrical model to predict such defect is expressed in the last part of this study (in section 4).
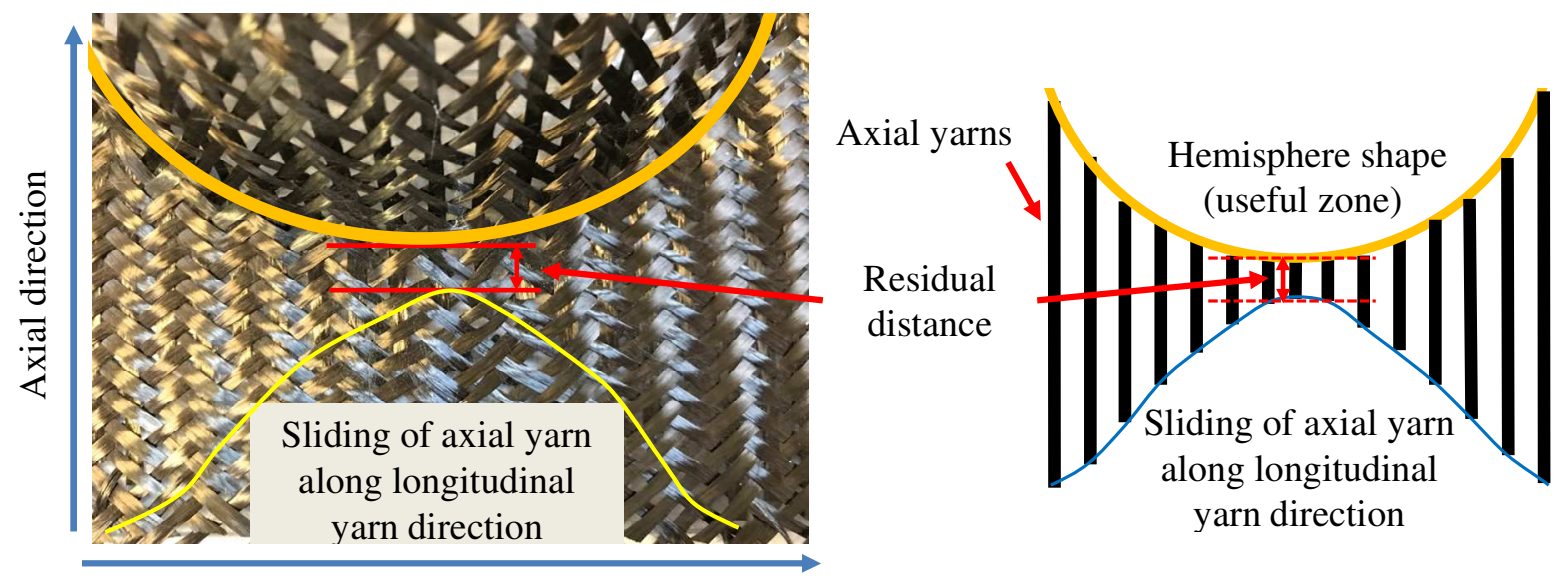

Transversal direction

Fig. 14. The large extent of yarns sliding along longitudinal yarn direction.

\subsubsection{Gaps and buckling}

The yarn sliding along radial yarn direction could lead to irregular gaps (seen in Fig.15), negatively impacting the uniformity of fibre density. It can be inferred from Fig.11 that less sliding at $0.05 \mathrm{MPa}$ could reduce the gaps magnitude. Furthermore, the buckling of bias yarns shown in Fig.15 is also detected. As the discussion above, the increasing blank-holder pressure can increase the bias yarns sliding along radial yarn direction towards the base of punch shape, so that the smaller circles, leading to the out-of-plane defect as buckling, are possibly produced. Due to the braiding method for such fabric, the axial yarns have more degree of freedom along longitudinal yarn direction than radial yarn direction. Consequently, no buckling is observed at axial yarns in the useful zone. 


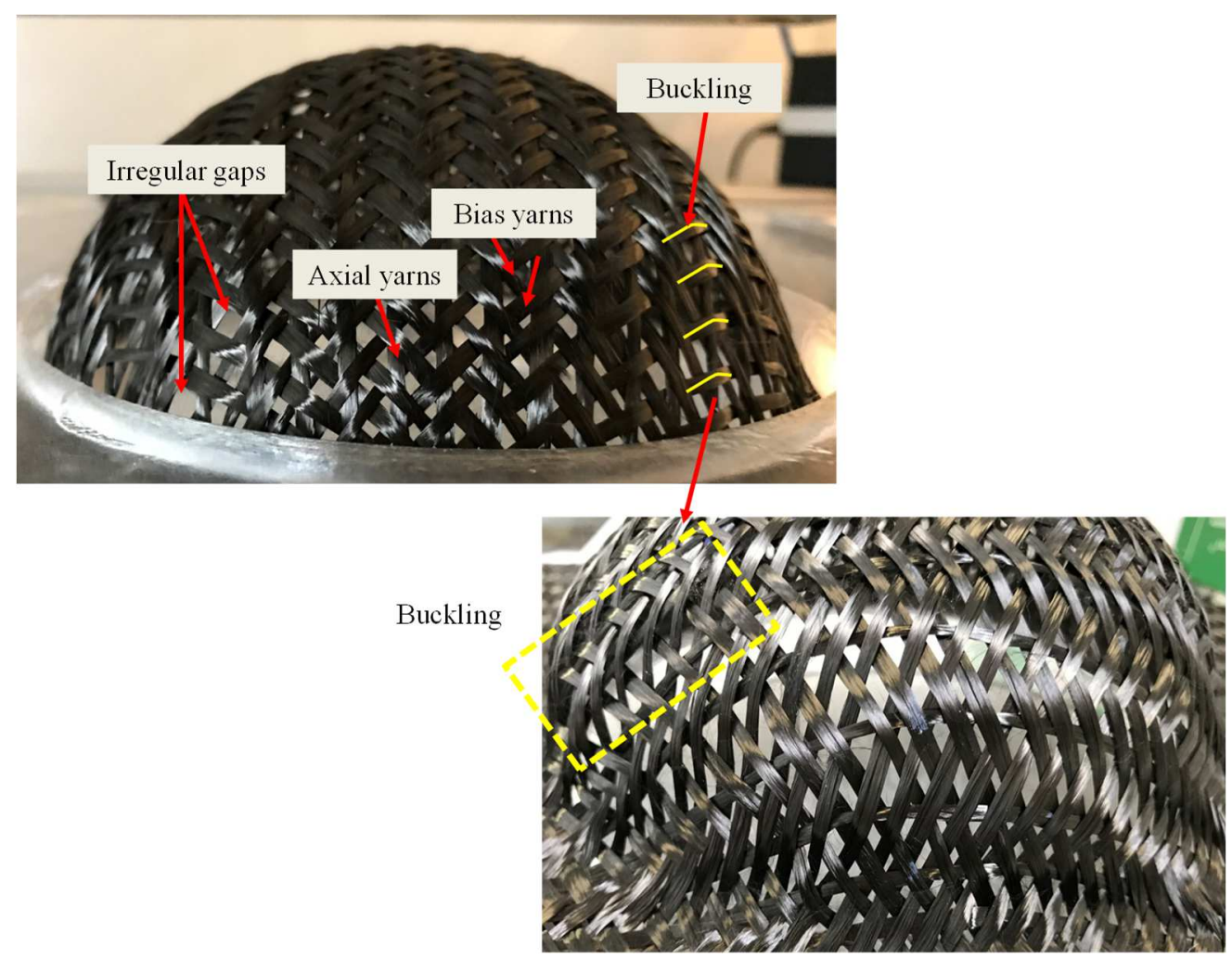

Fig. 15. The gaps and buckling in the useful zone.

\section{Geometrical models of the maximum sliding along longitudinal yarn}

\section{direction}

As discussed in section 3.3.1, the fibre vacancies are potentially generated by excessive yarns sliding along longitudinal yarn direction, resulting in poor quality of final composite parts. Based on the profiles of yarn sliding zones after preforming as shown in Fig.4 and Fig.7a, the geometrical models based on input parameters to predict maximum sliding for axial and bias yarn are sufficiently proposed to prevent such defect. Basically, the modelling is based on the hypotheses of quasi inextensibility, decoupling of the yarn directions and perfect contact.

\subsection{The prediction of maximum axial yarn sliding}

The axial yarns sliding along longitudinal yarn direction has identical sliding at the ends of yarn. The maximum sliding can be observed on the central axial yarn that sustains the 
maximum displacement of out-plane bending. Hence, the Fig.7a can be further simplified geometrically as shown in Fig.16. Based on the hypothesis of quasi inextensibility, the length of axial yarn is unchanged after preforming, and before preforming, the length of axial yarn $l$ is equal to the width of fabric $W$. Thus, Eq. 2 can be expressed after preforming as follows:

$$
2 T_{a}+\pi R=W
$$

where $T_{a}$ is a residual distance of axial yarn as shown in Fig.14, $R$ is the radius of punch shape, $S_{a}$ represents the maximum sliding of axial yarn that is presented in Fig.4. Thus, $T_{a}$ and $S_{a}$ can be expressed as follows:

$$
\begin{gathered}
T_{a}=\frac{W-\pi R}{2} \\
S_{a}=\frac{W}{2}-R-T_{a}=R\left(\frac{\pi}{2}-1\right)
\end{gathered}
$$

Apparently, the sliding stepping into the useful zone $\left(T_{a}<0\right)$ is undesired. Consequently, the criterion to prevent fibre vacancies for axial yarns $\left(T_{a} \geq 0\right)$ can be described as Eq.5.

$$
W \geq \pi R
$$




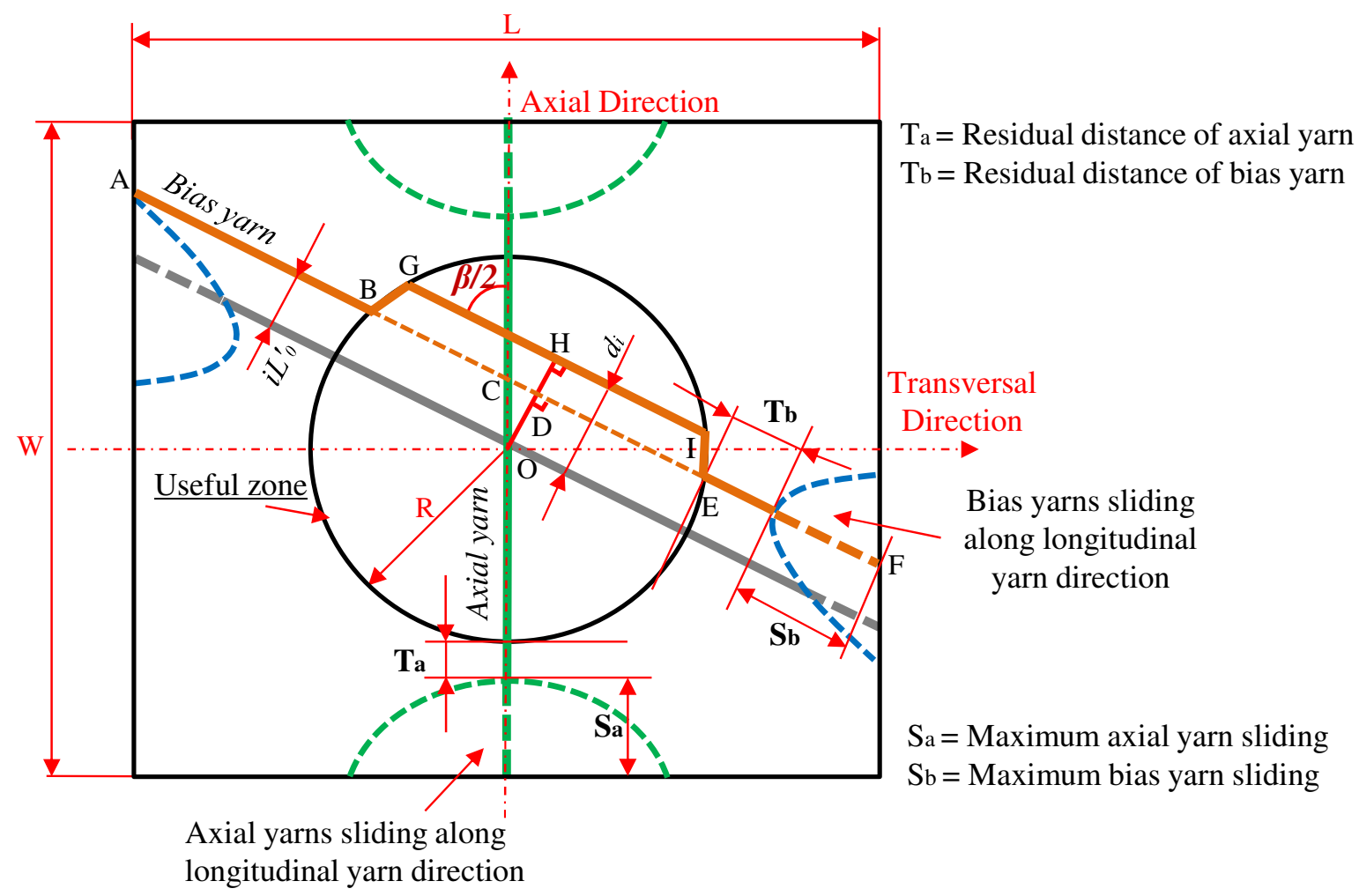

Fig. 16. A geometrical diagram presenting the yarns sliding along longitudinal yarn direction.

\subsection{The prediction of maximum bias yarn sliding}

Due to the non-identical deformability of bias yarns in the useful zone, the maximum bias yarn sliding is generated by the yarn that one end slide while another end does not. Thus, the AF can be deemed as the bias yarn with maximum sliding in Fig.16. Before preforming, the bias yarn $\mathrm{AF}$ can be numbered as $\mathrm{N}^{\circ} i$ depicted in Fig.3. During preforming, the bias yarn AF out of useful zone only generates sliding along longitudinal yarn direction, the distance between central bias yarn $\mathrm{N}^{\circ} 0$ to the bias yarn $\mathrm{AF}$ is thus not changed, and can be expressed by $i L_{0}^{\prime}, L_{0}^{\prime}$ represents the initial distance between two adjacent bias yarns as shown in Table 1.

In effect, due to the bias yarn sliding along radial yarn direction on the surface of hemisphere shape, the actual bias yarn AF is not straight after preforming. After preforming, the GI represents the actual position of the part of bias yarn AF in the useful zone in Fig.16. The length of $\mathrm{OH}$ depicts the vertical distance $\left(d_{i}\right)$ between central bias yarn $\mathrm{N}^{\circ} 0$ to GI, and 
the $d_{i}$ can be measured by preliminary experiments. The BE represents the part of bias yarn $\mathrm{AF}$ in the useful zone after preforming provided that there is no sliding along radial yarn direction. The midpoints of $\mathrm{AF}$ and $\mathrm{BE}$ can be geometrically pointed out as $\mathrm{C}$ and $\mathrm{D}$, respectively. Indeed, these two midpoints do not coincide geometrically so that it could explain the non-identical sliding of bias yarns. The length of BE is also the diameter of the circle punched perfectly by corresponding bias yarn AF in the useful zone. The length of AF hence can be calculated as follows equation (Eq. 6):

$$
l_{A F}=2 l_{A C}=\frac{L}{\sin (\beta / 2)}
$$

where $L$ is the length of fabric and $\beta / 2$ is the braided angle. Hence, the lengths of BD and CD can be expressed as Eqs. 7 and 8:

$$
\begin{gathered}
l_{B D}=\frac{l_{B E}}{2}=\sqrt{R^{2}-\left(i L_{0}^{\prime}\right)^{2}} \\
l_{C D}=\frac{i L_{0}^{\prime}}{\tan (\beta / 2)}
\end{gathered}
$$

thus, the length of $\mathrm{AB}$ can be calculated by Eqs.6, 7 and 8:

$$
l_{A B}=l_{A C}-l_{B C}=\frac{L}{2 \sin (\beta / 2)}-\sqrt{R^{2}-\left(i L_{0}^{\prime}\right)^{2}}+\frac{i L_{0}^{\prime}}{\tan (\beta / 2)}
$$

the length of GI can be expressed by Eq. 10. Provided quasi inextensibility, the residual distance of bias yarn $T_{b}$ can be described by Eq.11, the maximum bias yarn sliding $S_{b}$ thus can be expressed by Eq.12. Indeed, the lengths of BG and IE can be ignored because they are too small.

$$
l_{G H}=\frac{l_{G I}}{2}=\sqrt{R^{2}-d_{i}^{2}}
$$




$$
\begin{gathered}
T_{b}=l_{A F}-l_{A B}-\pi \times l_{G H}=\frac{L}{2 \sin (\beta / 2)}+\sqrt{R^{2}-\left(i L_{0}^{\prime}\right)^{2}}-\frac{i L_{0}^{\prime}}{\tan (\beta / 2)}-\pi \sqrt{R^{2}-d_{i}^{2}} \\
S_{b}=\frac{l_{A F}}{2}-l_{C D}-l_{D E}-T_{b}=\pi \sqrt{R^{2}-d_{i}^{2}}-2 \sqrt{R^{2}-\left(i L_{0}^{\prime}\right)^{2}}
\end{gathered}
$$

when $T_{b}=0$, the maximum sliding of bias yarn can be obtained. Consequently, the criterion aiming to prevent the fibre vacancies for bias yarns $\left(T_{b} \geq 0\right)$ can be put forward as Eq.11:

$$
L \geq 2 \sin (\beta / 2)\left(\frac{i L_{0}^{\prime}}{\tan (\beta / 2)}+\pi \sqrt{R^{2}-d_{i}^{2}}-\sqrt{R^{2}-\left(i L_{0}^{\prime}\right)^{2}}\right)
$$

The Fig.17 and 18 show the comparison of maximum yarn sliding $\left(S_{a}\right.$ and $\left.S_{b}\right)$ between experimental and theoretical results, the experimental results can be seen in Fig.6. It is evident that the theoretical and experimental values have a good correlation. The gap between theoretical and experimental values is almost up to $12.5 \%$ and $13 \%$ for maximum axial and bias yarn sliding, respectively. That indicates that the friction almost does not heavily impact on yarn sliding for such material, and also verifies that sliding is not influenced by changing blank-holder pressures. Through the geometric models is based on the hypotheses that indeed impact the accuracy, the models can roughly predict the maximum sliding during preforming. To avoid the defect of fibre vacancies, the models have a certain guiding significance. The next step will focus on the mechanical model of sliding that precisely characters the sliding behaviour. 


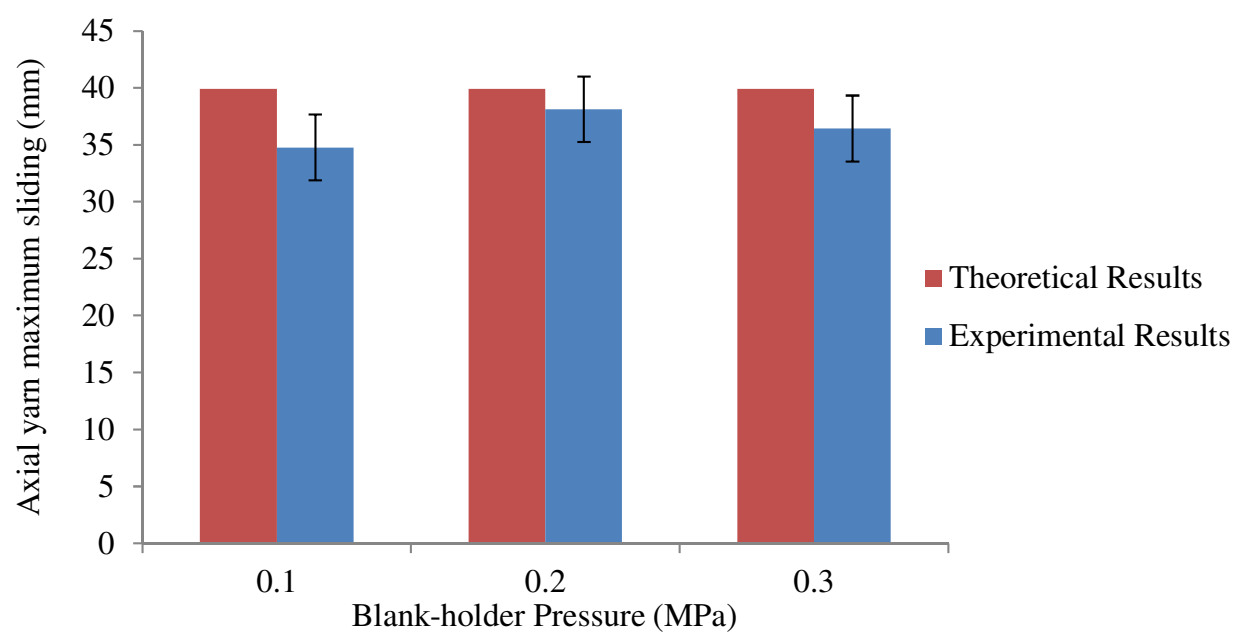

Fig.17. The comparison of maximum axial yarn sliding between theoretical and experimental results

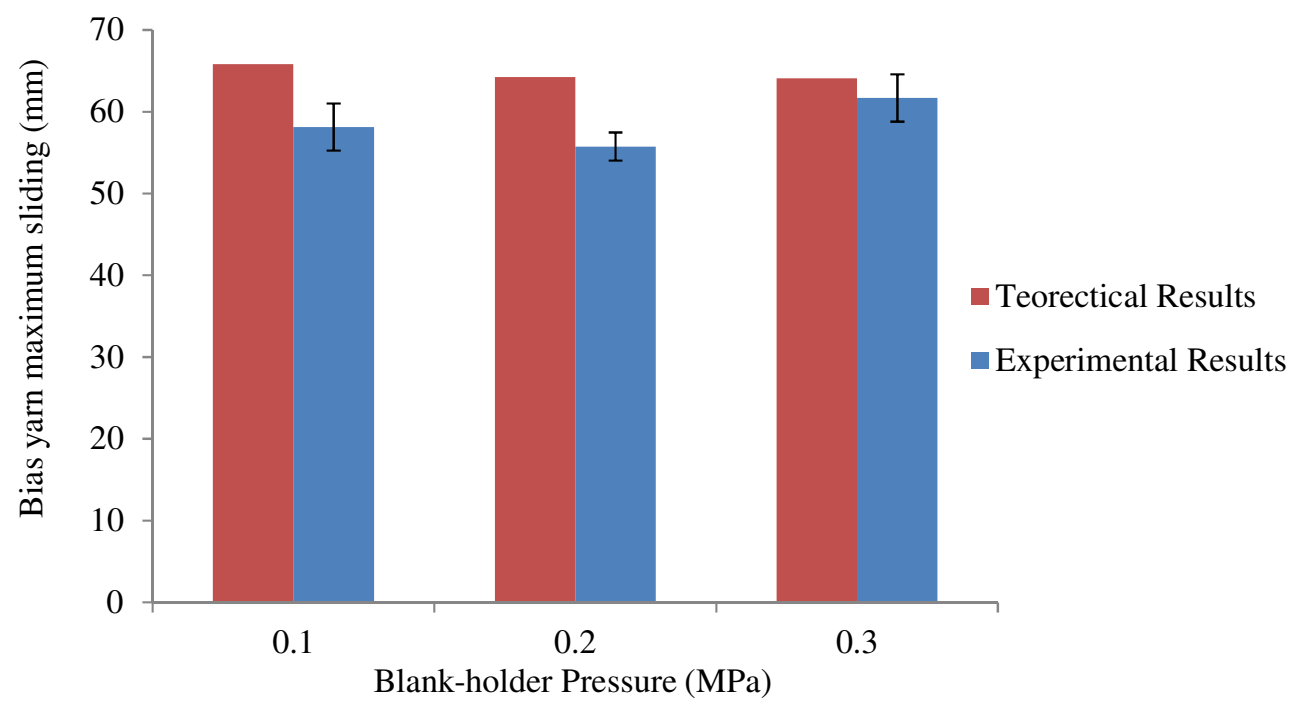

Fig.18. The comparison of maximum bias yarn sliding between theoretical and experimental results

\section{Conclusion}

The deformability of triaxial braided reinforcements during manufacturing is thoroughly analysed in the present study. The preforming behaviours of the triaxial braids are very interesting and much different from woven reinforcements, in particular the yarns sliding. The yarns sliding takes place along the longitudinal yarn direction due to the out-plane bending in the useful zone, presenting an equilibria yarn sliding at both ends of axial yarns and unbalanced yarn sliding at both of bias yarns. The yarns sliding along radial yarn direction is primarily produced by the shear effects along the tangent direction of hemisphere shape, and 
depends strongly on the location of the yarns at initial condition (the distance between the yarns and the centre of the fabric). Moreover, the in-plane shearing angle, which could characterize the extent of in-plane shearing behaviour, shows the negative value compared to correspondingly classical definition. The blank-holder pressure, one of the forming parameters, barely influence the yarns sliding along longitudinal yarn direction, but heavily impact the yarns sliding along radial yarn direction only increasing from 0.05 to $0.1 \mathrm{MPa}$. The defects, such as gaps, buckling and fibre vacancies, are directly associated with yarns sliding during preforming. The non-homogenous gaps and buckling are possibly caused by yarns sliding along longitudinal yarn direction. Fibre vacancies, the defect potentially generated by excessive yarns sliding along longitudinal yarn direction, can lead to a local material absence that negatively impacts the mechanical performance of final composite parts. Hence, the criteria preventing such defect are explored, and the geometrical models for maximum yarns sliding along longitudinal yarn direction are also proposed based on basic preforming parameters. The experimental and theoretical results have a good agreement, and it can be deduced that the yarns sliding depends mainly on the braiding angle, the dimensions of the fabric and punch shape.

\section{Acknowledgement}

The authors gratefully acknowledge financial support from the China Scholarship Council (CSC).

\section{Reference}

[1] Kruckenberg T, Paton R. Resin transfer molding for aerospace structures. Springer; 1998.

[2] Baran I. Advances in Composites Manufacturing and Process Design. Woodhead Publishing Series in Composites Science and Engineering; 2015. doi:10.1016/B978-178242-307-2.00016-6.

[3] Allaoui S, Cellard C, Hivet G. Effect of inter-ply sliding on the quality of multilayer interlock dry fabric preforms. Compos Part A Appl Sci Manuf 2015;68:336-45. doi:10.1016/j.compositesa.2014.10.017. 
[4] Labanieh AR, Garnier C, Ouagne P, Dalverny O, Soulat D. Intra-ply yarn sliding defect in hemisphere preforming of a woven preform. Compos Part A Appl Sci Manuf 2018;107:432-46. doi:10.1016/j.compositesa.2018.01.018.

[5] Bloom LD, Wang J, Potter KD. Damage progression and defect sensitivity: An experimental study of representative wrinkles in tension. Compos Part B Eng 2013;45:449-58. doi:10.1016/j.compositesb.2012.05.021.

[6] Ouagne P, Soulat D, Hivet G, Allaoui S, Duriatti D. Analysis of defects during the preforming of a woven flax reinforcement. Adv Compos Lett 2011;20:105-8.

[7] Sharma SB, Sutcliffe MPF, Chang SH. Characterisation of material properties for draping of dry woven composite material. Compos Part A Appl Sci Manuf 2003;34:1167-75. doi:10.1016/j.compositesa.2003.09.001.

[8] Ouagne P, Soulat D, Moothoo J, Capelle E, Gueret S. Complex shape preforming of a flax woven fabric; Analysis of the tow buckling and misalignment defect. Compos Part A Appl Sci Manuf 2013;51:1-10. doi:10.1016/j.compositesa.2013.03.017.

[9] Arbter R, Beraud JM, Binetruy C, Bizet L, Bréard J, Comas-Cardona S, et al. Experimental determination of the permeability of textiles: A benchmark exercise. Compos Part A Appl Sci Manuf 2011;42:1157-68. doi:10.1016/j.compositesa.2011.04.021.

[10] Ouagne P, Bréard J. Continuous transverse permeability of fibrous media. Compos Part A Appl Sci Manuf 2010;41:22-8. doi:10.1016/j.compositesa.2009.07.008.

[11] Mouritz AP, Bannister MK, Falzon PJ, Leong KH. Review of applications for advanced three-dimensional fibre textile composites. Compos Part A Appl Sci Manuf 1999;30:1445-61. doi:10.1016/S1359-835X(99)00034-2.

[12] Potluri P, Rawal A, Rivaldi M, Porat I. Geometrical modelling and control of a triaxial braiding machine for producing 3D preforms. Compos Part A Appl Sci Manuf 2003;34:481-92. doi:10.1016/S1359-835X(03)00061-7.

[13] Potluri P, Manan A, Francke M, Day RJ. Flexural and torsional behaviour of biaxial and triaxial braided composite structures. Compos Struct 2006;75:377-86. doi:10.1016/j.compstruct.2006.04.046.

[14] Ayranci C, Carey JP. Predicting the longitudinal elastic modulus of braided tubular composites using a curved unit-cell geometry. Compos Part B Eng 2010;41:229-35. doi:10.1016/j.compositesb.2009.10.006.

[15] Bilisik K. Three-dimensional braiding for composites: A review. Text Res J 2013;83:1414-36. doi:10.1177/0040517512450766.

[16] Branscomb D, Beale D, Broughton R. New Directions in Braiding. J Eng Fibres Fabr 2013;8:11-24.

[17] Potluri P, Manan A. Mechanics of non-orthogonally interlaced textile composites. Compos Part A Appl Sci Manuf 2007;38:1216-26. doi:10.1016/j.compositesa.2006.04.008.

[18] Kostar TD, Chou TW. A methodology for Cartesian braiding of three-dimensional shapes and special structures. J Mater Sci 2002;37:2811-24. doi:10.1023/A:1015893705790.

[19] Ayranci C, Carey J. 2D braided composites: A review for stiffness critical applications. Compos Struct 2008;85:43-58. doi:10.1016/j.compstruct.2007.10.004.

[20] Munro M, Fahim A. A Comparison of Helical Filament Winding and 2D Braiding of Fiber Reinforced Polymeric Components. Mater Manuf Process 1995;10:37-46. doi:10.1080/10426919508936925.

[21] Naik RA. Failure Analysis of Woven and Braided Fabric Reinforced Composites. J Compos Mater 1995;29:2334-63. doi:10.1177/002199839502901706.

[22] Dauda B, Oyadiji SO, Potluri P. Characterising mechanical properties of braided and 
woven textile composite beams. Appl Compos Mater 2009;16:15-31. doi:10.1007/s10443-008-9073-3.

[23] Hamila N, Boisse P, Sabourin F, Brunet M. A semi-discrete shell finite element for textile composite reinforcement preforming simulation. Int $\mathbf{J}$ Numer Methods Eng 2009;79:1443-66. doi:10.1002/nme.2625.

[24] Sjölander J, Hallander P, Åkermo M. Preforming induced wrinkling of composite laminates: A numerical study on wrinkling mechanisms. Compos Part A Appl Sci Manuf 2016;81:41-51. doi:10.1016/j.compositesa.2015.10.012.

[25] Hamila N, Boisse P. Simulations of textile composite reinforcement draping using a new semi-discrete three node finite element. Compos Part B Eng 2008;39:999-1010. doi:10.1016/j.compositesb.2007.11.008.

[26] Gereke T, Döbrich O, Hübner M, Cherif C. Experimental and computational composite textile reinforcement preforming: A review. Compos Part A Appl Sci Manuf 2013;46:1-10. doi:10.1016/j.compositesa.2012.10.004.

[27] Khan MA, Mabrouki T, Vidal-Sallé E, Boisse P. Numerical and experimental analyses of woven composite reinforcement preforming using a hypoelastic behaviour. Application to the double dome benchmark. J Mater Process Technol 2010;210:378-88. doi:10.1016/j.jmatprotec.2009.09.027.

[28] Ouagne P, Soulat D, Tephany C, Gillibert J. Measurement of the Appearance and Growth of Tow Buckling Defect in the Frame of Complex Shape Manufacturing Process by Using Fringe Projection Technique. Strain 2016;52:559-69. doi:10.1111/str.12206.

[29] Capelle E, Ouagne P, Soulat D, Duriatti D. Complex shape preforming of flax woven fabrics: Design of specific blank-holder shapes to prevent defects. Compos Part B Eng 2014;62:29-36. doi:10.1016/j.compositesb.2014.02.007.

[30] Nosrat Nezami F, Gereke T, Cherif C. Active preforming manipulation of composite reinforcements for the suppression of preforming defects. Compos Part A Appl Sci Manuf 2017;99:94-101. doi:10.1016/j.compositesa.2017.04.011.

[31] Gatouillat S, Bareggi A, Vidal-Sallé E, Boisse P. Meso modelling for composite preform shaping - Simulation of the loss of cohesion of the woven fibre network. Compos Part A Appl Sci Manuf 2013;54:135-44. doi:10.1016/j.compositesa.2013.07.010.

[32] Li XK, Bai SL. Sheet preforming of the multi-layered biaxial weft knitted fabric reinforcement. Part I: On hemispherical surfaces. Compos Part A Appl Sci Manuf 2009;40:766-77. doi:10.1016/j.compositesa.2009.03.007.

[33] Jauffrès D, Sherwood JA, Morris CD, Chen J. Discrete mesoscopic modeling for the simulation of woven-fabric reinforcement preforming. Int J Mater Form 2010;3:120516. doi:10.1007/s12289-009-0646-y.

[34] Peng X, Ding F. Validation of a non-orthogonal constitutive model for woven composite fabrics via hemispherical stamping simulation. Compos Part A Appl Sci Manuf 2011;42:400-7. doi:10.1016/j.compositesa.2010.12.014.

[35] Peng X, Rehman ZU. Textile composite double dome stamping simulation using a nonorthogonal constitutive model. Compos Sci Technol 2011;71:1075-81. doi:10.1016/j.compscitech.2011.03.010.

[36] Peng X, Guo Z, Du T, Yu WR. A simple anisotropic hyperelastic constitutive model for textile fabrics with application to preforming simulation. Compos Part B Eng 2013;52:275-81. doi:10.1016/j.compositesb.2013.04.014.

[37] Zhu B, Yu T, Zhang H, Engineering XT-CPB, 2011 U. Experimental investigation of formability of commingled woven composite preform in stamping operation. Compos Part B Eng 2011;42:289-95. 
[38] Boisse P, Hamila N, Vidal-Sallé E, Dumont F. Simulation of wrinkling during textile composite reinforcement preforming. Influence of tensile, in-plane shear and bending stiffnesses. Compos Sci 2011;71:683-92. doi:10.1016/j.compscitech.2011.01.011.

[39] Allaoui S, Boisse P, Chatel S, Hamila N, Hivet G, Soulat D, et al. Experimental and numerical analyses of textile reinforcement preforming of a tetrahedral shape. Compos Part A Appl Sci Manuf 2011;42:612-22. doi:10.1016/j.compositesa.2011.02.001.

[40] Wang P, Legrand X, Soulat D. Investigation about the manufacturing technique of the composite corner fitting part. Autex Res J 2014;14:111-20. doi:10.2478/aut-2014-0007.

[41] Allaoui S, Hivet G, Soulat D, Wendling A, Ouagne P, Chatel S. Experimental preforming of highly double curved shapes with a case corner using an interlock reinforcement. Int J Mater Form 2014;7:155-65. doi:10.1007/s12289-012-1116-5.

[42] Wang P, Legrand X, Boisse P, Hamila N, Soulat D. Experimental and numerical analyses of manufacturing process of a composite square box part: Comparison between textile reinforcement preforming and surface 3D weaving. Compos Part B Eng 2015;78:26-34. doi:10.1016/j.compositesb.2015.03.072.

[43] Jacquot PB, Wang P, Soulat D, Legrand X. Analysis of the preforming behaviour of the braided and woven flax/polyamide fabrics. J Ind Text 2016;46:698-718. doi:10.1177/1528083715591592.

[44] Mulvihill DM, Smerdova O, Sutcliffe MPF. Friction of carbon fibre tows. Compos Part A Appl Sci Manuf 2017;93:185-98. doi:10.1016/J.COMPOSITESA.2016.08.034. 